
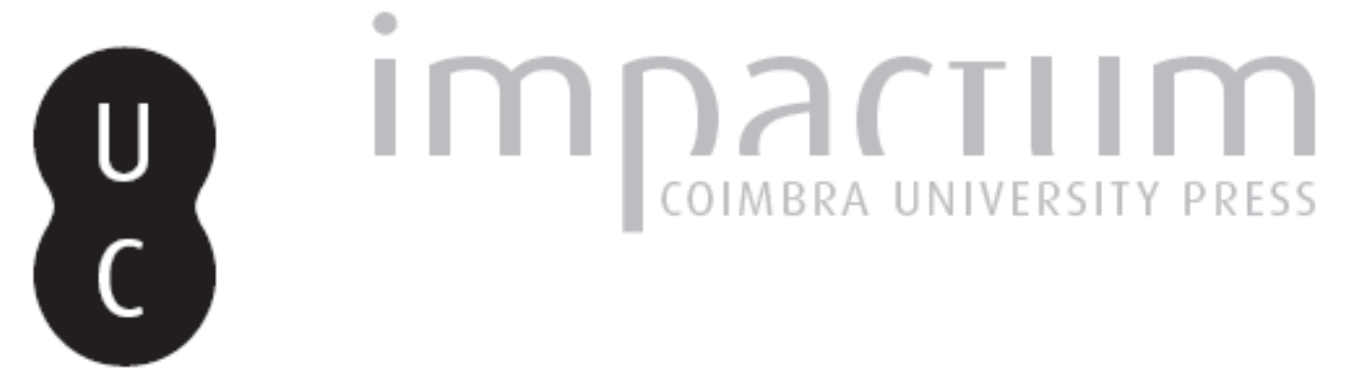

\title{
L. Antonio Vrso Liberti et Familia
}

\section{Autor(es): $\quad$ Ruivo, José da Silva}

Publicado por: Imprensa da Universidade de Coimbra

URL persistente:

URI:http://hdl.handle.net/10316.2/45511

DOI:

DOI:https://dx.doi.org/10.14195/1647-8657_31_6

Accessed : $\quad$ 26-Apr-2023 14:54:27

A navegação consulta e descarregamento dos títulos inseridos nas Bibliotecas Digitais UC Digitalis, UC Pombalina e UC Impactum, pressupõem a aceitação plena e sem reservas dos Termos e Condições de Uso destas Bibliotecas Digitais, disponíveis em https://digitalis.uc.pt/pt-pt/termos.

Conforme exposto nos referidos Termos e Condições de Uso, o descarregamento de títulos de acesso restrito requer uma licença válida de autorização devendo o utilizador aceder ao(s) documento(s) a partir de um endereço de IP da instituição detentora da supramencionada licença.

Ao utilizador é apenas permitido o descarregamento para uso pessoal, pelo que o emprego do(s) título(s) descarregado(s) para outro fim, designadamente comercial, carece de autorização do respetivo autor ou editor da obra.

Na medida em que todas as obras da UC Digitalis se encontram protegidas pelo Código do Direito de Autor e Direitos Conexos e demais legislação aplicável, toda a cópia, parcial ou total, deste documento, nos casos em que é legalmente admitida, deverá conter ou fazer-se acompanhar por este aviso.

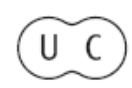


FACULDADE DE LETRAS

INSTITUTO DE ARQUEOLOGIA

\section{CONIMBRIGA}

VOLUME XXXI

,

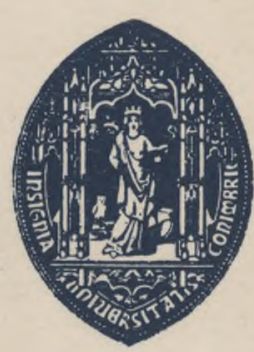

UNIVERSIDADE DE COIMBRA

1992 


\section{José DA SILVA RuIVO}

Licenciado em História (Variante de Arqueologia) — Universidade de Coimbra

\section{ANTONIO VRSO LIBERTI ET FAMILIA}

«Conimbriga» XXXI (1992), P. 119-154

RESUMO: Dedicada a L. Antonius Ursus pelos liberti et familia, a presente inscrição foi publicada pela primeira vez em 1972, por D. Domingos de Pinho Brandão. Apesar de ter passado despercebida durante muito tempo, assume-se como uma das epígrafes mais notáveis entre as descobertas até ao presente momento na cidade lusitana de Collipo. O autor analisa o seu conteúdo e as suas implicações jurídico-sociais, procurando inseri-la num momento particular da história da cidade - o da sua municipalização - e num quadro de contactos com a Itália, cuja influência o texto reflecte. Seguidamente interroga-se acerca do significado do termo familia, comentando várias inscrições peninsulares onde ele aparece referido.

$\mathrm{O}$ artigo termina com o estudo do gentilicio Antonius, primeiro no território português, com particular evidência para o conventus Scallabitanus e, depois, no contexto mais vasto da Hispania romana, onde esta família se afirmou como uma das grandes gentes.

RÉSUMÉ: Publiée la première fois en 1972 par D. Domingos de Pinho Brandão, la présente inscription est dediée à L. Antonius Ursus par ses esclaves et affranchis. Restée longtemps inaperçue, il s'agit d'une des plus importantes épigraphes trouvées dans la ville lusitanienne de Collipo, jusqu'à ce moment là. L'auteur analyse le contenu et les implications juridiques et sociales, en essayant son insertion dans un moment particulier de l'histoire de la ville - celui de sa municipalisation - et dans le cadre de 1 ' établissement de contacts avec 1 ' Italie, que le texte de 1 ' inscription laisse entendre. Il s'interroge ensuite sur le sens du mot familia, en commentant plusieures inscriptions de la Péninsule Ibérique ou il vient référé.

L'article finit avec l'étude du gentilicz Antonius, d'abord au Portugal, en attirant l'attention sur le conventus Scallabitanus et, après, dans le contexte plus élargi de l'Hispanie romaine, ou cette famille a joué un rôle très important. 
(Página deixada propositadamente em branco) 


\title{
L. ANTONIO VRSO LIBERTI ET FAMILIA
}

\author{
Notas sobre uma inscrição de Collipo (*).
}

\section{A inscrição e o seu estudo}

Pedestal de calcário com inscrição honorífica, proveniente de S. Sebastião do Freixo (Batalha). Actualmente, encontra-se guardado em instalações pertencentes ao Gabinete de Etnografia da Comissão Distrital de Turismo de Leiria.

De seç̧ão rectangular, apresenta a face epigrafada e as duas faces laterais trabalhadas. A face posterior foi rudemente desbastada, verificando-se igual procedimento para a superior. Esta última possui uma cavidade, talvez para utilização de forceps. Uma ou outra falha devida a maus tratos não impede, porém, a leitura da totalidade do monumento.

Dimensões: 63 x 53,5 x 50 .

Uució) (hedera) ANTO[N]IO / VRSO / LIBERTI (hedera) ET / FAMILIA

A Lúcio António Urso. Os libertos e a comunidade dos escravos.

Alt. das letras: 5,2.

(*) Ao Prof. Doutor José d' Encarnação, nosso mestre de Epigrafia, desejamos tributar o mais sincero reconhecimento pelas sábias pistas e sugestões que nos foi fornecendo durante a elaboração deste trabalho. Estamos igualmente gratos ao Prof. Doutor Jorge de Alarcão pela oportunidade das observações críticas que nos teceu. 
Brandão (D. de Pinho), Epigrafia romana coliponense, "Conimbriga", XI, 1972, pp. 42-44, n.Q IX. Encarnação (J. d), Pelo nome os conhecereis (subsídiospara o estudo da população romana da região de Leiria), comunicação apresentada ao II Colóquio Sobre História de Leiria e da Sua Região, Leiria, 29 e 30 de Novembro de 1991 (a publicar).

O texto está disposto por quatro linhas, ostentando ainda ligeiros vestígios de linhas auxiliares. A paginação não obedece a qualquer tipo de alinhamento, apesar de as duas primeiras linhas darem a ideia de que o lapicida ia seguir um eixo de simetria, no entanto, as duas últimas não respeitam essa intenção. Os caracteres são do tipo capital quadrada, de bom desenho, biselados. Nas linhas 1 e 3, a pontuação faz-se mediante a utilização de hederae distinguentes finamente desenhadas, a última das quais danificada. Na primeira linha, soltou-se uma lasca da pedra que fez desaparecer o segundo $\mathrm{N}$ da palavra ANTONIO, afectou a parte superior do I, atingindo ainda ao de leve os dois $\mathrm{O}$. Na linha 4, o último A de FAMILIA apresenta esfalhada a área correspondente à sua parte superior e à barra transversal.

Provavelmente relacionada com o levantamento de uma estátua em honra de L. Antonius Ursus, a presente epígrafe parece reflectir uma homenagem postmortem, facto que the confere um amplo cunho funerário.

$\mathrm{O}$ homenageado está identificado pelos tria nomina, à maneira latina; as implicações jurídico-sociais decorrentes da não-indicação da filiação e da tribo induzem-nos, porém, à primeira vista, a atribuir-lhe o estatuto de liberto, uma vez que a sua estrutura onomástica, como adiante explicitaremos, não parece revelar quaisquer indícios que o permitam relacionar com um estrato étnico tipicamente indígena.

Situado no grupo dos praenomina mais utilizados entre os Romanos, o prenome Lucius é vulgaríssimo $\mathrm{Q}$, havendo a destacar a sua superior utilização entre os indivíduos pertencentes ao ramo hispânico dos Antonii. Relativamente bem documentado no território actualmente português, sobretudo para a faixa atlântica compreendida entre os rios Tejo e Mondego, o prestigiado gentilicio Antonius foi, até ao momento, assinalado na área de Collipo apenas pela presente inscrição. Contudo, este nome arroga-se, em termos epigráficos, como o décimo terceiro mais bem representado na Hispânia $\left(^{2}\right)$. Quanto ao cognome Ursus, este ${ }^{*} 9$

(!) CAgnat (R)., Cours d'Épigraphie Latine, Paris, 1914, 4- ed., p. 39 (= Cours).

( $\left.{ }^{2}\right) \operatorname{KNAPP}(\mathrm{R} . \mathrm{C})$, The origin of provincial prosopography in the West, AncSoc, 9, 1979, p. 217 (= Prosopography).

Conimbriga, 31 (1992), 119-154 
antroponimo não é dos mais frequentes na onomástica latina da Península Ibérica $\left({ }^{3}\right)$, ocorrendo principalmente nas regiões orientais do Império $\left(^{4}\right)$, eventualmente relacionado com a popularidade gozada entre os primitivos cristãos $(5)$.

Em território português, Ursus foi registado no masculino em Mões, Viseu (CIL II 449); Fortios, Portalegre (FE 132); e Lisboa, onde, curiosamente, se assinala o seguinte epitáfio: C. An[tjonius | L. f Ur [s]us I h. s. $e\left(^{6}\right)$ E muito provável que estejamos perante um filho de Lúcio António Urso, dada a proximidade entre os dois nomes $\left({ }^{7}\right)$ e a indicação do patronímico Lucius, praenomen do homenageado em Collipo. Com uma onomástica bastante similar, temos, em Mérida, um Antonius Ursianus (ILER 4744), não sendo totalmente inverosímil a possibilidade de uma ligação familiar entre o homenageado em Colippo e os Antonii da capital provincial: dos agri coliponenses provém a inscrição funerária de Cláudia Sosuma, emeritense (ERC XXI). No feminino, encontra-se atestado em Lisboa $\left(^{8}\right)$ e numa cupa de Trigaches, Beja (IRCP 348).

Tratando-se aparentemente de um liberto, tudo aponta para a inclusão de Ursus no seio da burguesia coliponense, quem sabe se relacionado com actividades de natureza comercial ou artesanal.

Essa boa situação económica traduzir-se-ia, entre outras vantagens, na posse de um número relativamente elevado de servidores, libertos e escravos, designados na inscrição por liberti et familia, expressão que deixa transparecer estabelecimento de contactos entre a pequena cidade lusitana e a Itália. Esses contactos estão já de certa forma expressos na inscrição funerária do escravo Corinthus, natural de Colippo e falecido em Roma na flor da idade: D. M. S. | Corintho Helvi | Philippi ser. | ex Lusitania municip. | Collipponensi $\mid$ ann. XXI $\mid$ Victor et Celer fratri $\mid d$. $s . f C)$.

(3) UntermanN (J.), Elementos de un Atlas Antroponimico de la Hispania Antigua, Madrid, 1965, pp. 183-184, mapa 81.

$\left({ }^{4}\right)$ KaJAnto (I.), The Latin Cognomina, Roma, 1982 (reimp.), p. 329 (= Cognomina).

$\left({ }^{5}\right)$ KAJANTO, Cognomina, p. 88.

(6) CIL II $202=$ EO 82 = ILER 2398.

$\left({ }^{7}\right)$ CAGnAt, Cours, p. 68: no início do Império era frequente o filho mais velho, para além de receber o gentilicio paterno, receber também o cognome.

(8) CIL II $5004=$ EO 68 = ILER 2389.

H CIL VI $16100=$ ERC I.

Conimbriga, 31 (1992), 119-154 
SeráL. Antonius Ursus um colono? Ou tratar-se-á, antes, do liberto de uma família itálica? Era relativamente frequente o escravo, após a manumissão, tornar-se, por sua vez, patrono. E paradigmático o caso de Trimalquião, personagem do Satyricon de Petrónio que, tendo acumulado uma enorme fortuna através da especulação comercial, se torna, por seu turno, proprietário de numerosos escravos. Uma inscrição funerária proveniente da Itália, actualmente no Metropolitan Museum of Art, de Nova Iorque, é dedicada pelos liberti et libertae et familia ao patrono Q. Fábio Diogenes, um antigo escravo $\left({ }^{*} 10^{*}\right)$. O direito romano previa mesmo que um escravo pudesse possuir no seu pecúlio um ou vários escravos, adquiridos por doação, por compra ou por qualquer outro meio legal. $\mathrm{O}$ escravo de um escravo é geralmente designado por servus vicarius, embora, por vezes, possa também surgir referido como peculiaris, conservus ou verna $(\mathrm{n})$.

Ao estar relacionada com a possível vinda de imigrantes itálicos para a região, esta inscrição assume um papel de especial relevância, como testemunho para a romanização de Collipo. Se a datação que propomos estiver correcta, ou seja, a primeira metade do séc. I d.C., poderá corresponder a um período de afluxo de colonos, porventura em sintonia com a elevação de Collipo à categoria de municipium, promoção que o registo epigráfico de vários Tiberii Claudii nas imediações daquele centro urbano $\left.{ }^{12}\right)$ permitirá atribuir, hipoteticamente embora, aos reinados de Cláudio ou Nero (13).

É, no entanto, forçoso admitir que podemos estar na presença de uma concessão a título meramente individual, fruto de um acto de favor do princeps. Por outro lado, apesar de ser comummente aceite a localiza-

$\left({ }^{10}\right)$ Q. Fabio Diogeni | et Fabiae I Primigeniae | quae vixit cum eo | annis XXXXVIII liberti et libertae I et familia Q. Fabi I Diogenis posuerunt (informação do Prof. Doutor José d'Encarnação).

(n) LÉCRIVAIN (Ch.), Vicarius, in DA, t. 5, Paris, 1913, pp. 820-825.

(12) ERC p. 141. O gentilicio Claudius é, de longe, o mais bem representado no território da civitas, contando ao todo com nove exemplares, um dos quais de uma emeritense, seguido pelos Sulpicii, com cinco testemunhos.

(13) AlARCÁO, (J.), Identificação das cidades da Lusitânia portuguesa e dos seus territórios, in "Les Villes de Lusitanie Romaine: hiérarchies et territoires",

Paris, 1990, p. 26. Contra a ideia de uma política de Cláudio em favor das províncias espanholas, cfr. NONY (D.), Claude et les espagnols, sur un passage de L'"Apocoloquintose", MCV, 4, 1968, pp. 51-71 (= Claude et les Espagnols). Segundo este autor, a Espanha ocuparia apenas um lugar subalterno na política ocidental daquele imperador. 
ção do oppidum no monte de S. Sebastião, a verdade é que, até agora, as escavações aí realizadas não puseram a descoberto quaisquer vestígios monumentais daquela antiga cidade $\left({ }^{14}\right)$, pelo que, contrariamente ao que se passou em Conimbriga (15), não dispomos, para já, de nenhuma indicação cronológica acerca da execução de um programa de renovação urbanística condizente com a aquisição do novo estatuto jurídico.

E aqui recorremos, mais uma vez, à epigrafia, cujos dados parecem apontar para a fixação de um substrato itálico na região, o mais tardar, por volta de meados do século I d.C (16). Atente-se nos seguintes epitáfios, o primeiro de Leiria: M. Granius \Vegetus arm. $\mid$ XXVh. s. e. s. 1.1.I. IIulia Lobessa \ coniugip. c. ( $\left.{ }^{17}\right)$; e o segundo de S. Sebastião do Freixo: Helviae I Maxsum [a]le Valerius \Severus $\mid$ cliens $\left({ }^{18}\right)$. Aparentemente, os textos datam da primeira metade do séc. I e documentam gentilicios característicos da Península Itálica. Os Granii, que na Hispânia contam com cerca de duas dezenas de testemunhos (cfr. ILER p. 600), distribuídos sobretudo ao longo da fachada mediterrânica da Citerior e da Bética, eram uma importante família de Puteoli, dos finais da República (19). É, de facto, na Campânia, que avultam os seus portadores (31 em CIL X), mas também no Lácio $\left({ }^{20}\right)$, na Úmbria e na Etrúria (22 em CIL XI) $\left({ }^{21}\right)$. Fora da Itália, merecem igualmente menção os Granii do Norte de África, sobretudo os de Lepcis Magna, com assento no Senado e a numerosa comunidade residente em Delos (22). Pertencerá M. Granius Avitus a esta família de

(14) Alarcáo (J.) e Oleiro (J. M. B.), Escavações em S. Sebastião do Freixo (concelho da Batalha), "Conimbriga", 8, 1969, pp. 1-12.

$\left.{ }^{(15}\right)$ Foram realizadas em Conimbriga duas renovações urbanas, uma na época de Augusto, outra na dos Flávios, esta correspondente à concessão do estatuto municipal à cidade: AlARCÁo (J.), O Domínio Romano em Portugal, Mem Martins, Europa-América, 1988, pp. 70-74 (= Domínio).

(16) A idêntica conclusão chegaram José d'Encarnação e M. da Conceição Lopes para o município vizinho de Eburobritium (FE 170).

(17) ERCXXXV.

(is) ERCXII.

$\left(1^{9}\right)$ ForCELLINI, Lexicon Totius Latinitatis, t. V, Pádua, 1940, s.v. Granius $(=$ Lexicon).

${ }^{(20)}$ Sobretudo em Ostia, onde existiu uma basilica ou porticus Graniana (CIL XIV 4715) e em Roma.

(21) SCHUlze (W.), Zur Geschichte Lateinischer Eigennamen, Berlim, 1966, pp. 237 e 237 a (=Eigennamen $)$.

(22) LASSĖRe (J.-M.), Ubique populus, Paris, 1977, pp. 92 e 179. Sobre o número dos Granii africanos, veja-se Pflaum (H.-G.), Onomastique de Cirta, in “Afrique Romaine, Scripta varia I”, Paris, 1978, pp. 172-173. 
homens de negócios "internacionais" ou ao numeroso séquito dos seus clientes?

Quanto aos Helvii, são frequentes em toda a Itália, particularmente na Campânia, na Lucânia e no Lácio (23). Pinho Brandão (op. cit. pp. 9 e 52-53) estabelece, e muito bem, a ligação entre a Hélvia Máxima, da inscrição de S. Sebastião, e o Helvius Philippus da inscrição de Roma, atrás transcrita. É crível que Hélvio Filipe tenha residido e talvez nascido em Collipo, de onde terá levado para a Cidade Eterna o escravo Corinthus e os irmãos, Victor e Celer. Se dúvidas existissem relativamente ao estabelecimento de contactos entre Collipo e a Itália, este monumento desvanecê-las-ia. Que esta gens era influente na vida local daquele município lusitano, mostra-o claramente o facto de o epitáfio de Hélvia Máxima ter sido mandado lavrar por um seu cliente.

De S. Sebastião é oriunda outra lápide, hoje infelizmente perdida, não menos interessante: Q. Laerio $\mid$ Quirinae [sic] $\mid$ Scipioni an. XXX $\mid$ Quintilla $Q . \mid$ fil. mater $\mid$ filio $\mid$ pientissimo $\left({ }^{24}\right)$.

Vários aspectos ressaltam da análise do texto, o primeiro dos quais é o facto de a tribo vir indicada por extenso e em genitivo. Em segundo lugar, a ocorrência do gentilicio Laerius, que - a estar correctamente grafado - constituirá um hapax na epigrafia do mundo romano. Por último, a paleografia da inscrição, gravada, segundo dizia J. Callado em 1890, "em caracteres latinos do século de Augusto" (25). Ora, na linguagem dos autores do século passado, estes caracteres costumam corresponder à capital quadrada de inícios do séc. I d.C., o que é plenamente confirmado pela ausência da fórmula D.M.S., que só começa a ser habitual nos epitáfios, de meados daquele século em diante ${ }^{(26)}$.

Quanto a Laerius, tanto pode representar um caso ímpar, como tratar-se de uma má leitura ou de um erro do lapicida. Atendendo a que se conhece em Collipo o gentilicio Laberius, documentado inclusivamente na pessoa de uma flaminia provincial - Labéria Gala de seu nome $\left({ }^{27}\right)$, parece-nos aceitável optar antes por aquela forma gentílica.

(23) SCHULZE, Eigennamen, p. 162.

(24) ERC XIII.

${ }^{25}$ ) CALLADO (J.), Inscripção romana, "Distrito de Leiria", de 24 de Maio de 1890.

(26) LASSÈRE (J.-M.), Recherches sur la chronologie des épitaphes païennes de VAfrica, AntAfr, 7, 1973, pp. 120-121 (= Chronologie des épitaphes païennes), onde o autor traça um quadro sinóptico relativo à evolução do formulário sepulcral no Norte de África, na Gália e na Itália.

(27) ERC IV. O outro testemunho reporta-se a uma Laberia Maxuma (n.Q XXV). 
Finalmente, a questão da tribo. A Quirina, tribo de Collipo, constitui, por excelência, a tribo a que foram adscritos os habitantes das cidades elevadas pelos Flávios à categoria de municípios, não se conhecendo, até ao presente momento, nenhum exemplo seguro da sua atribuição por Cláudio na Hispânia ${ }^{28}$, pelo que uma datação recuada é meramente hipotética. Não obstante, parece-nos de considerar a eventualidade de uma municipalização júlio-claudiana para Collipo, que J. de Alarcão admite ter podido ocorrer também em relação a Sellium, Ammala zAritium Vetus $\left({ }^{29}\right)$.

No tocante ao motivo ou motivos que estiveram na origem da dedicatória a Lúcio António Urso, podemos aventar a seguinte hipótese: ao morrer, aquele terá efectuado várias disposições em favor dos seus escravos e libertos, algumas das quais poderão ter incluído o legado de uma soma em dinheiro ou em bens e a manumissão de alguns servos $\left({ }^{30}\right)$.

Estes, reconhecidos pela liberalidade do seu senhor, resolveram mostrar publicamente a sua gratidão, mediante a dedicatória de uma inscrição e o levantamento de uma estátua. Questão que vem a propósito, é a de saber qual o contexto arqueológico a que estaria associado tal monumento, de características excepcionais, face aos hábitos epigráficos da região. Uma resposta tentadora passaria pela sua colocação num recinto público, como o forum da cidade, solução que a ausência de qualquer referência expressa à intervenção da ordo local, em princípio, não autoriza. Outra hipótese, plena de cabimento, foi-nos sugerida pelo Prof. Doutor José d'Encarnaçâo, de acordo com a qual, a inscrição e a estátua se destinariam a figurar no recinto funerário desta família, quiçá à entrada do mausoléu, à semelhança do que encontramos, por exemplo, em cidades como Pompeia ou Herculano ( $\left.{ }^{31}\right)$.

(28) NONY, Claude et les Espagnols, pp. 57-58.

(29) Alarcão (J.), O estado e o governo local, in "Nova Historia de Portugal" (dir. de J. Serrão e A. H. de Oliveira Marques, coord, de J. de Alarcão), vol. I, Editorial Presença, Lisboa, 1990, p. 390.

${ }^{(30}$ O acto de libertar um escravo era considerado meritório aos olhos da sociedade romana. Petrónio \{Satyricon 71.1) coloca na boca de Trimalquião as seguintes palavras: os escravos também são homens e mamaram o mesmo leite que nós, a despeito do destino que os maltrata. Mas, em minha vida e brevemente, hão de saborear a água da liberdade. Em poucas palavras, liberto-os a todos no meu testamento. Veja-se ainda ALFÖLDY (G.),La manumisión de esclavos y la estructura de la esclavitud en el Imperio Romano, PLAV, 9, 1973, pp. 99-123.

(31) Sobre os monumentos sepulcrais daquelas cidades, cfr. KocKEL (V.), Die Grabbauten vor dem Herkulaner Tor in Pompeji, Mainz am Rhein, 1983. 
É de supôr que, associando-se em homenagem ao nome do patrono, os servidores de L. Antonius Ursus pretendessem usufruir do prestígio que lhe seria reconhecido em Collipo.

\section{O significado de liberti et familia}

Deixámos prepositadamente para este ponto o comentário à expressão liberti et familia, aqui registada pela primeira vez, ao que julgamos saber, na epigrafia latina da Península, mas que parece ser comum em Roma, nomeadamente em inscrições provenientes de monumentos funerários colectivos ${ }^{32}$ ), com frequência alusivas aos servidores de importantes personagens Libertorum et $\mid$ familiae $\mid$ Scriboniae et Corneli Marceli f eius, relativa aos servidores da primeira esposa de Augusto ( ${ }^{33}$ ), on Libert, et I familiae $\mid$ L. ArruntiL. $f \backslash$ Ter., referente aos libertos e aos escravos de um cônsul ( $\left.{ }^{34}\right)$, ou ainda Libertorum | et libertarum $\mid$ et familiae $\mid$ C.Anni C. f. Cor. I Pollionis ( $\left.{ }^{35}\right)$. Este C. Annius Polio terá sido, talvez, aquele que, segundo Tácito (Ann. 6.9), esteve implicado em 32 d.C. na conjuração de Sejano contra o imperador Tibério ou o pai dele ( $\left.{ }^{36}\right)$. Não faltam, também, exemplos relativos aos servidores de personagens ricas, mas menos influentes: Familiae L. Coccei et liberteis | et eorum | Dasius disp. de suo fac. coer. ( $\left.{ }^{37}\right)$, ou Liberteis et familiae $\mid$ L. Noni L. F. Pap. et

(32) Veja-se por exemplo: CIL VI5931,6068,7395,9268,9320,9321,9322, 9323, 11998, 26197, 26258, 35199, 36474.

(33) CIL VI 26033.

(34) ILS $7851=$ CIL VI 5931.

(33) CIL VI 7395 = ILS 7852. Poderíamos citar ainda outros exemplos significativos, como CIL VI 26258, monumento dos libertos e da familia de T. Septumus Sabinus, provavelmente o edil curul referido em Plínio, N.H. 34.93.

(36) CIL Vip. 1051.

(37) CIL I $^{2} 1286=$ CIL VI $9320=$ ILLRP 785. Segundo S. Panciera e N. Pétrucci, a referência a um dispensator indica com frequência a presença de uma familia numerosa e importante, geralmente pertencente a membros da classe senatorial ou a personagens de relevo. Aqueles autores chamam ainda a atenção para o facto de três quartos dos dispensatores conhecidos epigraficamente em Roma terem encontrado sepultura nos columbaria das principais famílias romanas (PANCIERA, S. e PÉTRUCCI, N., Monumentum familiae et libertorum gentis Mariae, BCAR, 92 (2), 1987-1988, pp. 309-310). Temos inclusivamente casos em que os dispensatores doavam o sepulcro di familia e aos conservi, como em CIL VI 9321 = ILS 7853: In front, p. XIIII familiae et liberi. | Vitellior. | Eumaeus disp. dat. | In agr. p. XXXXV.

Conimbriga, 31 (1992), 119-154 
Antoniae libertorum ( $\left.{ }^{38}\right)$ e Libertor. I et famil. $\mid$ Seneci Surae $\mid$ in fr. $p$. $X X X V$ I in ag. p. $X X X V\left({ }^{39}\right)$, indicando os dependentes de individuos de estirpe nobre, embora desconhecidos.

Estas inscrições, procedentes, na maior parte dos casos, de columbaria, para além do seu profundo significado funerário, detêm ainda assinalável importância no plano social, na medida em que, ao indicarem os nomes dos patronos - indivíduos geralmente poderosos que edificavam ou mandavam edificar, eles mesmos, tais monumentos sepulcrais - veiculam uma certa ideologia do grupo dominante. Como acentua G. Fabre, as "elites" nada mais faziam que prestar homenagem ao seu próprio nome e traduzir, numa realidade arquitectónica nova e significativa pelas suas dimensões, a coesão e a importância dos laços de dependência $\left({ }^{40}\right)$.

Se, como já ficou demonstrado, em Roma existe uma ligação evidente entre a utilização da expressão liberti et familia e as práticas funerárias dos escravos e libertos pertencentes às classes dirigentes $\left({ }^{41}\right)$, 0 mesmo já não parece suceder noutras regiões do Império, onde surge com menos frequência, e não já tanto com carácter funerário, mas mais honorífico, não perdendo, apesar de tudo, o seu cunho "elitista". Assim acontece na seguinte inscrição da Dàcia: - I [Anniae ?] | Luci[llae] | Augus[tae] \Imp. Veriafug.] |Armenia[ci] \[Par]th[ici] | maxim[i]|lib. et familia \et $\mid$ leguli aurariar., em honra de Ânia Lucila, esposa de Lúcio Vero ${ }^{(42}$ ), ou numa outra de Hippo Regius, na África Proconsular: T. Flavio T.f Quir. Macro \duumviro flaminiper|petuo Ammaedarensium |praef gentis Musulamio |rum curatori frumenti comparandi in annona 1 Urbis facto a divo Nerva Traliano Aug. proc. Aug. a[dpr] aedis saltus Hipponifens.] et Theve[st]ini proc. provinc[i]ae Sficjiliae collegum Larum Caesaris n. et liberti et familia item conductores qui in regione

(38) CIL I ${ }^{2} 1346=$ VI 23006.

(39) CIL VI $26197=$ ILS 7854.

${ }^{(40)}$ FABRE (G.), Libertus. Recherches sur les rapports patron-affranchi à la fin de la République romaine, École Française de Rome, Roma, 1981, p. 151 (= Libertus).

$\left.{ }^{41}\right)$ idem, ibidem, p. 152, chama a atenção para o facto de, em Roma, estas práticas colectivas de enterramento terem ganho a maior importância, ligadas, por um lado, à carestia dos terrenos e, por outro, à importância numérica das familiae dependentes das grandes gentes.

(42) IDR III (3), 283. 
Hipponi[ens]i consistent, homenageando T. Flavius Macer, procurador imperial sob o reinado de Trajano $\left({ }^{43}\right)$.

Imputada ao conjunto dos libertos e escravos de um senhor, a expressão liberti et familia tende a destacar os libertos do conjunto dos serviçais propriamente ditos $\left({ }^{44}\right)$; não faltam, porém, argumentos para a inclusão dos libertos na familia dos servidores $\left({ }^{45}\right)$.

O termo familia é anterior à Lei das XII Tábuas $\left({ }^{46}\right)$ e deriva do osco farnel, de onde teria dado origem a famulus (servo, escravo) $\left({ }^{47}\right)$. Esta etimologia fixa o sentido primitivo ât familia como o conjunto dos famuli que habitavam na mesma casa, sujeitos à autoridade de um senhor $\left({ }^{48}\right)$. Posteriormente, o termo foi objecto de uma grande evolução semântica, passando a incluir também os libertos $\left({ }^{49}\right)$ e a implicar uma comunidade de domicílio ${ }^{(50)}$, aproximando-se daquilo que hoje entendemos por família. Esta extensão do sentido primitivo é facilmente compreensível, uma vez que os filhos in potestate e a uxor in manu, não estavam menos sujeitos ao poder paternal que os próprios escravos $\left({ }^{51}\right)$. Neste sentido, podemos distinguir no direito romano pelo menos duas espécies de família, encarada por um lado como o conjunto de servi e pessoas livres - filius familia, uxor in manu, netos, filhos adoptivos, libertos e clientes - submetidas à autoridade de um paterfamilias e, por outro, como o conjunto dos agnados — parentes por consanguinidade — descendentes de um mesmo antepassado comum, parte da gens, ou a própria gens ${ }^{(52}$ ).

( $\left.{ }^{43}\right)$ LeVeau (Ph.), L 'aile II des Thraces, la tribu des Mazices et les praefecti gentis en Afrique du Nord, AntAfr, 7, 1973, p. 177, nQ 41.

(44) Em CIL I21703 = ILLRP 285, a expressão familiam suam manumisit tem por intenção destacar os libertos do comum dos escravos.

${ }^{(45)}$ FABRE, Libertus, pp. 332-333.

(46) Weaver (P. R. C.), Familia Caesaris. A social study of the emperor's freedmen and slaves, Cambridge, 1972, p. 299 (=Familia Caesaris).

${ }^{(47)}$ Festus, De verb, signif., p. 87: famuli origo ab Oscis dependet apud quos servus famel nominabantur, unde et a vocata.

(48) ForCellin, Lexicon, t. II, Pádua, 1940, s. v. Familia', Benveniste (E.), Vocabulaire des institutions indo-européennes, Paris, 1969, p. 358.

(49) Nesta acepção, veja-se, por exemplo, CIL XII4887: L. S. I familia!libertorum libertarum | C. Iuli Aucti.

${ }^{(50)}$ FABRE, Libertus, p. 131.

(51) BAUdRY (F.), Familia, in DA, t. II, Paris, 1896.

${ }^{52}$ TLL, t. VI, Leipzig, 1812-1826, col. 239-240, s. v. Familia', RADIN (M.), Gens, familia, stirps, $\mathrm{CPh}, 9,1914$, p. 238. Relativamente às várias acepções de familia, cfr. ainda LEONHARD (R.), Familia, in RE, t. VI (2), Estugarda, 1909. 
Familia é, de facto, uma expressão polivalente - como reconhece Ulpiano (Dig. 50.16.195): Familiae appellatio varie accepta est - que serve para identificar o núcleo de parentesco, os escravos, os bens, indicando que tudo é propriedade do chefe de família. Subjaz a este conceito um princípio patrimonial, compreendendo as pessoas in manu, livres e escravos e, juntamente com elas, os bens móveis e os imóveis, as res mancipi e as res nec mancipi (53).

Uma questão que nos parece pertinente é a de saber qual o número de servos que compunham a familia. Escreve Cícero (Pro A. Caecina 19.55): uno servulo familiae nomen non valere, "a palavra família não se deve aplicar a um único escravo". E, mais à frente, prossegue o eminente jurisconsulto: familia intelligamus quae constet ex servis pluribus quin unus homo familia non sit, "entenda-se que \& familia é composta por vários servos e que um só homem não pode formar uma familia".

Mais conciso a este respeito é Ulpiano (Dig.5D.16.40 §3): quindecim liberi homines populus est, totidem servifamilia, totidem vincti ergastulum, "quinze homens livres constituem o povo; o mesmo número de servos, a familia; o mesmo número de presos, o ergástulo".

Parece-nos, portanto, que afamilia seria constituída por um grupo mais ou menos numeroso de servos, consoante o poder económico de cada proprietário. Eram as famílias ricas que mais escravos possuíam; a própria legislação augustana permitia a um senhor possuir mais de 500 servi; contudo, entre as famílias medianamente ricas o número de escravos seria significativamente menos elevado: G. Alfóldy cita o caso da província do Nórico, em que o maior número de escravos numa única casa, documentado epigraficamente, é de seis (CIL III 4962) ( ${ }^{54}$ ).

Enquadradas nesta perspectiva que temos vindo a desenvolver, registámos algumas referências ao termo familia em inscrições latinas da Península. Assim acontece em Adra, na Bética, onde o liberto Suavis e o escravo Faustus erigiram uma dedicatória aos Lares e ao Génio da familia: C. C. N. | Suavis l. et |Faustus vilic. Lar. et Genium | cum aedicula primi in familia $d$. s. $d . d .{ }^{(55)}$. Faustus era um vilicus, tinha por

(53) Levi (M. A.), Familia, Servitus, Fides. Indagación en torno a la dependenda humana en la sociedad romana, "Gerión”, 1, 1983, p. 189.

${ }^{54}$ ) Alföldy (G.), A historia social de Roma, Editorial Presença, Lisboa, 1989, pp. 152-153.

(55) CIL II 1980. MANgas MANJARres (J.), Esclavos y libertos en la España romana, Salamanca, 1971, pp. 77, 203 (=Esclavos y libertos). 
missão supervisionar o trabalho dos outros escravos nas explorações agrárias do patrão ${ }^{56}$ ). Encontra-se aqui subjacente o conceito d familia rustica, conjunto de escravos que executavam as tarefas agrícolas nos fundi das villae pertencentes aos senhores (57), definido por oposição a familia urbana, comunidade de escravos associados à residência citadina do dominus $\left({ }^{58}\right)$.

Em Tarragona, um epitáfio assinalando a construção de um monumento sepulcral em memória de Antonia Clementina, a mando do marido, P. Rufius Flaus, determinava que os terrenos circundantes à sepultura fossem entregues aos libertos e às libertas da familia da esposa, a fim de que estes, atendendo ao obséquio devido à patrona, ficassem a tratar do sepulcro, devendo esta obrigação transmitir-se aos seus descendentes: D. M. I Antoniae Clementinae ux. P. Rufius Flaus $\mid$ m.f et s. viv. in. memorium perpetuam | hortos coherentes sive suburbanum tradidit $\mid$ lib. libertabusque ex familia ux. Marnilo Antrocio | Helenae Tertulinae excepitq. ne quis eos | venderet set per genus ipsorum possessio decurret I vel per atnatos vel manumissos $\left({ }^{59}\right)$.

Antonia Clementina possuía os seus próprios escravos (familia), na qual estavam incluídos alguns libertos e libertas: libertis libertabusque ex familia uxoris, o que milita em prol do que atrás afirmámos, quando incluímos os libertos nafamilia dos servidores. As próprias relações entre libertos e servos de um mesmo patrono eram estreitas; muitas vezes, as responsabilidades que alguns libertos assumiam dirigindo a familia, os mantinham, aos olhos do patrono ou de terceiros, no seio desta última $\left({ }^{60}\right)$. Nesta linha podem ser interpretadas as inscrições colectivas de Roma CIL VI5691 = ILS 7850: Familiae $\mid$ A. Allieni $\backslash$ in fr. p. XV $\mid$ in ag. p. XVI $\mid$ et familiae I PollaeMinluciae Q.ft CIL VI6213: Familia T. Statili Tauri, mencionando os servidores de três membros da ordem senatorial.

(56) Cato De Agr., VII, 2: vilicus familiam exerceat, consideret quae dominus imperaverit fiant.

${ }^{(57)}$ WeAVer, Familia Caesaris, p. 4; MANGAS Manj ARRES, Esclavos y libertos, pp. 74-78. Para um maior desenvolvimento, cfr. MARTIN (R.), Familia rustica: les esclaves chez les agronomes latins, "Actes du Colloque 1972 sur l'esclavage", Paris, 1974, pp. 267-298.

(58) CIL XII 1025; WeAVER, Familia Caesaris, p. 4.

$\left.{ }^{59}\right)$ RIT 368. Era habituai os patronos incumbirem aos servidores esta missão de cuidarem do sepulcro, intenção igualmente manifestada por Trimalquião (Satyricon, 71.8)

(60) FABRE, Libertus, p. 335. 
Significado diverso reproduz o epitáfio métrico dt Aelia Hygia, posto a descoberto na longinqua Dàcia. Mandou lavrar Èlio Valentino, à "liberta e esposa digna de apreço, que o tempo cruel arrebatou à familia" $\left({ }^{61}\right)$. Familia seria aqui utilizada na acepção de conjunto de servos e de pessoas livres, incluindo a uxor in manu e ofilius familias, que constituem uma mesma casa, sob a dependência do paterfamilias. Como já vimos, este conceito tornou-se extensivo a uma parte da gens ou à própria gens e é precisamente neste contexto, irrefutavelmente mais amplo, que deverá ser examinada uma homenagem de Baena: M. Pompeius $Q$. $f$ Gal. Icstinis I Ilvir. primus de familia \Pompeia $\left({ }^{62}\right)$. Numa demonstração pública de orgulho, por um dos seus ter ascendido pela primeira vez a um destacado cargo na edilidade local, alguns membros da gens Pompeia de Itucci \{conventus Astigitanus) dedicaram a inscrição.

$\mathrm{Na}$ epigrafia peninsular, casos há em que o termo familia nos aparece relacionado com o tipo de organização social das populações préromanas. Numa lápide funerária de Folda del Sueve (Astúrias) parece ler-se: [P]o ?...Dalgen[i Ter. fil(i) ?] a[n]|norum LI ex | gente Ratrium । [fa] milia suorum e $\left(x\right.$ ?) testamento ?) $\left(f^{3}\right)$. Familia designará, neste caso, um grupo de pessoas ligadas entre si por laços de sangue ou de parentesco, unidade nuclear situada em plano hierarquicamente inferior ao da gens. $\mathrm{O}$ defunto e toda a sua família pertenciam à gens Ratrium, uma unidade organizativa indígena, de carácter suprafamiliar, que actuava simultaneamente como unidade social ( $\left.{ }^{64}\right)$.

Por fim e num campo bastante peculiar, observe-se uma epígrafe votiva de Fuente Redonda (Uclés), dedicada a Airo peía familia Oculensis Usetana: Deo Alironi fecit falmilia 0|cul(en)s(is) Use[t(ana)] \C(aius) Titinni(us) | Crispinus ( ${ }^{65}$ ). Somos da opinião qut familia se encontra,

(61) IDRIII (3) 159: D. M. I Aelia Hygia vixit $\mid$ annis XVIII $\mid$ Ael Valent[inus dec. ?] I col. Apul fl. I libertae et coniugi | gratae | quam tempus durum | rapuit familiam $\mid$ pu(a)e simul Dacia te | voluitpossedit $\mid$ Micia secum, have | puella multum adque I in aevum vale.

(62) CIL II1855 = ILER 1675, CURCHIN (L. A.), The local magistrates of Roman Spain, University of Toronto Press, Toronto-Buffalo-London, 1990, p. 153, nQ 154.

(63) CIL II 5749 = ERA 35 = ILER 5495, GonZÁLEZ RodrígueZ(M. e.), Las unidades organizativas indígenas del área indo-europea de Hispania, Vitoria/Gasteiz, 1986, p. 133, nQ 171 (= Unidades organizativas indigenas). Seguimos a leitura proposta por F. Diego Santos, que não deixa, contudo, de ser hipotética.

(64) GONZÁLEZ RodríGuEZ, Unidades organizativas indígenas, p. 112.

(65) CIL II $5888=$ ILER 714. 
aqui muito distante da acepção primitiva, entendida como conjunto de escravos. O adjectivo geográfico Oculensis, correspondendo à forma mais antiga até hoje encontrada, relativamente aos habitantes de Uclés( $\left.{ }^{66}\right)$, leva-nos a atribuir-lhe o significado de um grupo de indivíduos de uma comunidade ou do conjunto de habitantes de uma localidade. Igual interpretação merece o texto da estela de Valhermoso de la Fuente (Cuenca), dedicada a Aemilia Panthia pela familia Alabanensis $\left({ }^{67}\right)$.

\section{O gentilicio Antonius}

No período republicano, o gentilicio Antonius era muito usual entre os romanos, tanto nas famílias patrícias como nas de ascendência plebeia. A gens romana dos Antonii vangloriava-se de ser descendente de Anton (Anxccnjj-œiios), filho de Hércules ( ${ }^{68}$ ).

$\mathrm{Na}$ lista dos seu membros mais ilustres contam-se vários cônsules $\left({ }^{69}\right)$, um dos quais o triúnviro Marco António. Também a esta família pertenceram os três M. Antonii Gordiani (238-244), conhecidos na História por Gordiano I, II e III, após efemeramente terem cingido a púrpura imperial $\left({ }^{70}\right)$.

Como referimos logo no início deste trabalho, este nome encontra-se ampiamente difundido na onomástica latina da Hispânia, ultrapassando a centena e meia de testemunhos (Quadro I). No caso do território actualmente português, os Antonii estão relativamente bem documentados, destacando-se claramente de todas as outras a região outrora abrangida pelo antigo conventus Scallabitanus, com especial saliência para os centros urbanos de Scallabis e Olisipo.

De resto, nesta última cidade, para além da já mencionada inscrição a C. Antonius Ursus, provavelmente filho do homenageado em Collipo, é digno de referência o monumento honorífico CIL II $4993=$ EO $82=$

(66) BlÁzQuez Martínez (J. M.), Religiones primitivas de Hispania. I- Fuentes literarias y epigráficas, Roma, 1962, pp. 168-169.

(67) Rodríguez Colmenero (A.), Cuenca romana. Contribución al estudio epigrafico (II), "Lucentum", II, 1983,pp. 324-326:2). M. S. |Ae. Panthiaean. ILXXX familia $\mid$ Alabanensis ?

${ }^{(68)}$ FORCELLINI, Lexicon, t.V, s. v. Antonius.

(69) ROLdÁn HeRVAS (J. M.), Repertorio de epigrafia y numismática latinas, Salamanca, 1969, p. 107, apresenta urna lista de doze cônsules saídos daquela família.

(70) PIR, I, pp. 159-163.

Conimbriga, 31 (1992), 119-154 
ILER 1265: MatidiaeAug. |Fel. lui Olisipo $\mid$ per $\mid$ Q. Antonium Gallum I T. Marcium Marcianum \Ilvir., dedicado à sobrinha de Trajano, onde se regista um $Q$. Antonius Gallus, duúnviro de Olisipo. O exercício de tal magistratura confere-lhe, bem corno à sua família, um lugar de destaque no contexto sócio-económico e político do município olissiponense, tanto mais que este é, até ao momento, o único membro conhecido da gens Antonia a ocupar um cargo municipal na Lusitânia, durante o Alto Império ${ }^{(71)}$.

Ainda de Olisipo, CIL II $242=$ EO $76=$ ILER 2401: Q. Pompeius Q.fi[L] I [Ti ?]phush. s. e. $\mid$ Antonia Omul[i]a $\mid$ h. s. e., recorda uma liberta daquela gens.

No ager olisiponensis detectámos a presença deste gentilicio em duas inscrições de Oeiras, em memória át Antonia Amoena ( ${ }^{72}$ ), dedicadas respectivamente pelo pai, Antonius Amoenus, e pela mãe, Arethusa, num ambiente que nos parece servil; é provável que se encontre ainda representado em Caparide, Cascais, numa lápide posta a Iulia (?) Amoena pox G. Antonius (?) Avitus, veterano da XXII Legião Pia Fiel (?) (73).

Outra cidade onde os Antonii estão bem representados é, como dissemos, Santarém, outrora capital conventual da Lusitânia, onde se destacam dois monumentos funerários do séc. II, dedicados respectivamente a G. Antonius Lupus: D. M. | M. Antoni $\mid$ M. f. Gal. Lupi $\mid$ olisiponesis ( $\left.{ }^{74}\right)$ e a $Q$. Antonius Celer: D. M. $\backslash$ Q. Antoni M. $f \backslash$ Gal. Celeri I olisiponesis (75), cidadãos romanos naturais de Olisipo, inscritos na tribo Galéria. A importância de Scallabis, na sua qualidade de centro políticoadministrativo, poderá ter estado na origem da sua vinda para esta cidade.

As semelhanças ao nível do formulário das inscrições, a estrutura onomástica e a indicação do mesmo patronímico, concorrem para os identificarmos como irmãos. Temos também como plausível uma ligação à família do duúnviro olissiponense, $Q$. Antonius Gallus.

(71) FRANCISCO MARTIN (J.), Los magistrados municipales en Lusitânia durante el Alto Imperio, MHA, I, 1977, p. 237.

(72) CIL II $270=$ ILER 4161; CIL II $5009=$ ILER 3987.

(73) EnCARnaÇÃo (J. d'), Inscrições romanas de Cascais, "Museu - Biblioteca do Conde de Castro Guimarães", Boletim nQ 2, Cascais, 1971, pp. 103-104 = ILER $6387=$ AE 1981491 .

(74) CIL II $327=$ EO 144A = ILER 5380.

(75) CIL II328 = EO 144B = ILER 5381. Em Cerro de la Poza assinala-se um Antonius Celer, sacerdote, em inscrição votiva a Júpiter (CIL II 742 = ILER 668). 
A estas duas inscrições poder-se-á ainda ligar uma terceira: Antoniae I M. $f$. Marcianae | annor. XXII ( $\left.{ }^{76}\right)$, mencionando uma presumível filha de M. Antonius Lupus. Levanta-se-nos, porém, o problema da proximidade temporal das inscrições, que de facto parece não existir; contudo, só a utilização de critérios paleográficos mais ou menos seguros, com base numa observação directa dos monumentos, poderá lançar um pouco mais de luz na questão.

De qualquer modo, um dado que daqui se pode extrair é a existência de laços familiares entre as gentes Antonia e Mareia, atendendo a que a forma cognominai Marciana é formada a partir do gentilicio Marcius $\left({ }^{77}\right)$; vinculação essa já de certa forma patente na dedicatória erigida à sobrinha de Trajano pelos cidadãos de Olisipo, onde T. Marcius Marcianus surge, a par de $Q$. Antonius Gallus, no exercício do duunvirato.

Novamente em Santarém, foi encontrada uma outra inscrição, dedicada por Iulia Rufina à filha, Antonia Modesta: D. M. I Antoniae |Modestae |ann. XXXXI lidia Rufina | mater filiae | pientissimae | posuit $\mid$ h. s. e. $\left({ }^{78}\right)$, muito provavelmente a mesma personagem que, em Ferreira do Zêzere, surge ao lado do genro,L. Avillius Celer, numa dedicatória ^Antonia Maxuma: D. M. I Antoniae Maxumae | Antonia Modesta ma $\mid$ ter etL. Avillius Celer $\mid$ maritus ex testamento $f$. c. $\left({ }^{79}\right)$. Estão presentes três gerações - mãe, filha e neta - que procuraremos reproduzir no stemma que se segue:

$[\ldots]$ Antonius $[\ldots]^{00}$ Iulia Rufina

Antonia Modesta

Antonia Maxuma ${ }^{\circ \circ}$ L. Avillius Celer

Da defunta de Ferreira do Zêzere, conhecemos uma homónima, em inscrição igualmente funerária, proveniente de Alenquer : D. M. I Antoniae Maximae |an. XXXII \Caesia Amoena | mater filiae | pientissimae

(76) CIL II 329 = ILER 2296.

(77) KaJanto, Cognomina, p. 150.

(78) CIL II $330=$ ILER 4280.

(79) CIL II $335=$ ILER 3740.

Conimbriga, 31 (1992), 119-154 
I h. s. e. $\left.{ }^{80}\right)$, pese embora o facto de existir uma ligeira diferença em relação à grafia do cognome: Maxima em vez de Maxuma.

Do que temos vindo a dizer, dois aspectos nos merecem reparo. Em primeiro lugar, a ligação da gens Antonia à AvMia, aqui representada num dos raros testemunhos fornecidos pela epigrafia peninsular. Esta antiga família, de origem etrusca $\left({ }^{81}\right)$, é conhecida na Hispânia por inscrições provenientes de Sevilha (CIL II1215), Córdova (HAE 2053) e em marcas cerâmicas de Tarragona (CIL II 4970(75> 76>77), 4974(3)), Braga - onde foram encontradas as marcas de terra sigillata itálica dos officinatores L. Avillius Sura (Arezzo) e S. Avillius Manius( ${ }^{82}$ ) - e Conimbriga( $\left.{ }^{83}\right)$. O ramo itálico dos Avillii Celeres terá fornecido um legado à Africa antes de 113 d.C. ou um procônsul após esta data $\left({ }^{84}\right)$. Desta família saiu ainda o consul suffectus do ano $156 \mathrm{~d}$. C, A. Avillius Urinatius Quadratus. Geza Alföldy considera a possibilidade de este personagem ter desempenhado as funções de governador da Lusitânia à volta de 154, julgando reconstituir o seu nome numa inscrição fragmentada de Olisipo (CIL II $189=$ EO 21) (85). RIT 223 regista-o como cognome, na pessoa de C. Valerius Avillius, veterano da VII Legião Gèmina, natural de Nemausus.

O segundo aspecto a atrair a nossa atenção são os laços de parentesco estabelecidos entre os Antonii e os Iulii, uma das famílias mais influentes do conventus, nomeadamente de Olisipo, onde são, de longe, os mais bem representados $\left({ }^{86}\right)$. Proveniente dessa cidade, uma inscrição alude a um C. Iulius Rufinus, edil designado (CIL II225 = EO 42), quiçá parente dtlulia Rufina, avó át Antonia Maxuma. A ligação entre as duas gentes encontrar-se-á ainda expressa na inscrição funerária do Lorvão: $C$.

(«o) CIL II 271 = ILER 4297.

(81) SCHULZE, Eigennamen, Berlim, 1966, p. 73.

(82) Delgado (M.), Marcas de oficinas de sigillatas encontradas em Braga. II, CadArq, série II, 2, 1985, pp. 13-14.

(83) Das escavações desta cidade provém uma marca da oficina de Avillius Manius, cfr. AlarCão (A.), Les sigillées italiques, in Fouilles de Conimbriga-LV. Les sigillées, $\mathrm{n} Q 234$, PI. XII e XIII.

${ }^{(84)}$ LASSÈRE, Chronologie des épitaphes païennes de l Africa, p. 14.

$\left.{ }^{85}\right)$ Alföldy (G.), Fasti Hispanienses. Senatorische Reichsbeamte und Offiziere in den spanischen Provinzen des römischen Reiches von Augustus bis Diokletian, Wiesbaden, 1969, pp. 142f, 219 e 227.

(86) EO, pp. 279-280. 
Valerius Iulianus Seiliensis |annor. XVIII h. s. e. s. t. t. I. | M. Antonius Iulianus $\backslash$ fratri piissimo $\backslash$ faciendum curavit $\left({ }^{87}\right)$. Como se pode observar, estes dois indivíduos, apesar de irmãos, usam gentilicios diferentes, mas mantêm cognomes iguais. Para Thylander, esta situação fica a dever-se ao facto de o nascimento do filho mais velho ter ocorrido antes de a mãe contrair o matrimonium iustum ( $\left.{ }^{88}\right)$. Assim, o filho mais velho, que, segundo deduzimos, seria M. Antonius Iulianus, era fruto de uma relação anterior ao connubium, pelo que usaria o gentilicio materno, o irmão mais novo, saído de um casamento legal, usaria o nomen paterno. Iulianus, forma cognominai obtida a partir do gentilicio Iulius ( ${ }^{89}$ ), teria sido herdado da mãe. A indicação da origo, Seiliensis está, por certo, relacionada com a cidade de Sellium, definitivamente localizada em Tomar ${ }^{\left({ }^{90}\right)}$.

Situação idêntica parece verificar-se num epitáfio de Conimbriga: D.M.S. I Antonio $\mid$ Flavino $\mid$ annorum $\mid$ XXXXFlavius Fla $\mid$ vuspater $\mid$ et Antonia $\mid$ mater etFla via soror $\mid$ filio pienissimo $\mid f c$. $\left({ }^{91}\right)$, recordando Antonio Flavino. Intervêm como dedicantes Flavius Flavus, Antonia e Flavia, respectivamente pai, mãe e irmã do defunto. Pode tratar-se, no entanto, de um daqueles casos de desconhecimento das regras clássicas de transmissão dos nomes $\left({ }^{92}\right)$, o que nos situaria, indubitavelmente, num contexto pouco romanizado.

Ainda relativamente a Antonio Flavino, convém referir que, ao tratarem desta inscrição, os autores de Fouilles de Conimbriga II, p. 67, nota 17, referem a proximidade onomástica com o séxviro júnior $C$. Antonius Flavinus, de Évora (CIL II 115), testemunho que Hübner considerou forjado por André de Resende a partir de CIL V 4365 ( ${ }^{93}$ ). Não obstante as reticências colocadas pelo sábio alemão, R. Étienne aceitou a autenticidade do monumento e inseriu-o na sua lista de seviri Augustales ( $\left.{ }^{94}\right)$.

${ }^{(87)}$ VASCONCELos (J. Leite de), Inscrição funerária doLorvão, AP, 19,1914, pp. 365-366; ILER 5410.

${ }^{(88)}$ THYLANDER (H.), Etude sur TEpigraphie Latine, Lund, 1952, p. 91.

(89) Kajanto, Cognomina, pp. 33 e 148.

${ }^{(90}$ ) PONTE (S. da), Tomar. Historia e geografia humanas no tempo e no espaço, “Arqueologia da Região de Tomar", 1,1985, pp. 18-21; ALARCão, Domínio, p. 48.

(91) CIL II 366 = ILER 4861 = Fouilles de Conimbriga II 39.

(92) Cagnat, Cours, p. 68.

${ }^{93}$ CIL II, p. 805: Titulum falsum esse dudum intelexi, i. e. a Resendio confictum fortasse ad exemplum tituli vol. V 4365.

(94) Etienne (R.), Le Culte Impérial dans la Péninsule Ibérique d'Auguste à Dioclétien, Paris, 1974 (reimp.), p. 254 (=Culte). 
Mais recentemente, José d'Encarnaçâo reafirmou o carácter apócrifo da inscrição $(93 *)$.

Passando agora à área geográfica abrangida pelo conventus Pacensis, encontramos este gentilicio documentado em apenas cinco epígrafes, das quais somente três constituem testemunho seguro (IRCP 331,464 e 486), já que, nas outras duas, a hipótese de se ler Antonius -ia, é apenas tida como provável (IRCP 298 e 387). Deste conjunto sobressai nitidamente das restantes a dedicatória IRCP 486: Endovellico | sacrum | Antonia L. [f] I Manliola $\mid$ e. v. | signum argenteum [d. d. ?]. Este ex-voto, proveniente do santuário campestre de S. Miguel da Mota (Terena, Alandroal), recorda a oferta de uma estátua de prata a Endovélico por Antonia Manliola, sinal evidente do poder económico da doadora.

À semelhança do que sucede para o conventuspacensis, também para o conventus Bracaraugustanus ( ${ }^{96}$ ) não abundam os dados epigráficos relativos à gens Antonia, presente em Alvarelhos (Santo Tirso) ( ${ }^{97}$ ), Tagilde (Guimarães) (98*), Braga ("), Aldeia Nova (Miranda do Douro) $\left({ }^{10 \circ}\right)$ e Saldanha (Miranda do Douro) $\left({ }^{101}\right)$. Na sua maioria, identificam indivíduos pertencentes a um estrato populacional composto, principalmente, por indígenas romanizados, excepção feita ao pacense M. Antonius Au-gustinus, soldado da Legião VII Gèmina, falecido em Bracar a Augusta.

Relativamente aos testemunhos epigráficos desta família no nosso território, parece-nos importante colocar em evidência dois aspectos: em

(95) ENCARNAÇ̃̃o (J. d'), Recensão bibliográfica: Fouilles de Conimbriga.

II-Epigraphie et Sculpture, por R. Etienne e G. Fabre (epigrafia), P. e M. Lévêque

(escultura), Paris, 1976, AB, XXVIII-XXXII, 1971-75; IRCP p. 443.

(\%) Por razões que se prendem com uma maior comodidade de exposição, resolvemos incluir no conventus bracar augustanus duas inscrições da área de Miranda do Douro (inscr. 24 e 25), possivelmente já integrada no conventus asturicensis.

Relativamente a esta questão veja-se ALARCÃO, Domínio, pp. 58-59 e TrANOY (A.), La Galice romaine. Recherches sur le Nord-Ouest de la Péninsule Ibérique dans l'Antiquité, Paris, 1981, pp. 160-162 (= Galice romaine).

(97) SANTARÉM (C. M. F.), Uma inscrição romana de Alvarelhos —Sto Tirso,

"Santo Tirso", I (1), 1977, pp. 161-170 = AE 1977451.

(98) CIL II $6288=$ ILER 696.

(") CIL II 2425 = ILER 5467.

$\left({ }^{10 \circ}\right)$ Mourinho (J. M.), Epigrafia latina de entre Sabor e Douro, desde o falecimento do Abade deBaçal -1947, "Brigantia", VII (1-2), 1987, p. 104, nQ 30.

(101) idem, ibidem, p. 113, nQ 44.

(102) Mantas (V.G.), As cidades maritimas da Lusitânia, in "Les villes de Lusitanie romaine: hiérarchies et territoires”, Paris, 1990, pp. 160-173. 
primeiro lugar, existe um grupo numeroso de indivíduos identificados com os tria nomina, sinal de acentuada romanização, apesar de, neste conjunto, termos apenas três menções à tribo. Seguidamente, há a referir que, no conventus Scallabitanus, cerca de sessenta por cento dos testemunhos estão relacionados com o meio urbano, tendo à cabeça a capital Scallabis e Olisipo, talvez o maior centro portuário da Lusitânia $\left({ }^{102}\right)$, que terá decerto funcionado como ponto de penetração de colonos itálicos, embora deste numeroso grupo nos pareça que só $Q$. Antonius Gallus eL. Antonius Ursus possam estar directamente relacionados com a Península Itálica.

No que diz respeito à difusão dos Antonii na Hispânia, ressalta a sua especial concentração nos centros urbanos, nomeadamente nas zonas portuárias da Tarraconense e da Bética (Quadro I). A primazia vai para Tarraco, sede provincial, que terá albergado o núcleo mais importante desta gens, em solo peninsular. Entre o escol da cidade encontram-se vários indivíduos portadores deste nome. Um deles, L. Antonius Saturninus, ocupou sucessivamente as funções de edil, duúnviro e flàmine provincial (103). Este último cargo foi de igual modo desempenhado por Cn. Antonius Avitus (RIT 255) e pelo intercatiense L. Antonius Modestus (104). Ainda nesta cidade, está referenciado um membro da ordem equestre, L. Antonius Silo, prefeito da Ora Marítima durante o período flaviano (RIT 162).

Uma análise ao Quadro II, permite-nos constatar que é efectivamente na Tarraconense que se encontra a esmagadora maioria dos Antonii titulares de importantes cargos políticos, religiosos e militares, principalmente nas áreas de Carthago Nova $\left({ }^{105}\right)$, Valentia $\left({ }^{106}\right)$, Saguntum $\left({ }^{107}\right)$,

(103) G. AlFÖLDY (RIT 257, p. 141), considera a possibilidade de este personagem ser o pai do senador com o mesmo nome, cônsul substituto do ano 83 d.C., adlectus por Vespasiano.

(104) RIT 256. L. Antonius Modestus é oriundo de uma família indígena de Intercatia (conventus cluniensis), cidade onde desempenhou todos os cargos municipais, antes de se tomar sacerdote do culto imperial. Saliente-se que o exercício de uma magistratura municipal, como a edilidade ou o duunvirato, era o trampolim a que recorriam frequentemente as burguesias das cidades para o acesso ao fiammato, uma das suas maiores ambições (cfr. ÉTIENNE, Culte, p. 224).

(105) HAE 42 = ILER 6318: C. Antonius P. f Coi. Balbus, aedilis. A Colina é uma das tribos urbanas de Roma.

(106) IRV 23: L. Antonius Crescens, aedilis, Ilvir, flamen. Em Valência, os Antonii são a família mais bem representada, logo seguidos dos Iulii, a quem se encontravam associados (IRV 22) e dos Fabii (KNAPP, Prosopography, p. 202 e 213).

${ }^{(107)}$ ELS 42 e 43: L. Antonius Numida, praefectus fabrum, tribunus militum legionis I Italica.

Conimbriga, 31 (1992), 119-154 
Aeso (108), Clunia $\left({ }^{109}\right)$, Calagurris ${ }^{\left({ }^{n o}\right)}$, Barbadillo del Pez $\left({ }^{\mathrm{m}}\right)$ e Castromao $\left({ }^{*}\right.$ III 112).

Estes dados traduzem bem a influência desta família na vida daquela província e o seu considerável potencial económico, com toda a certeza fruto dos rendimentos da propriedade fundiária, mas também da actividade comercial, quer se trate do comércio regional, quer do comércio internacional, feito por via marítima.

$\mathrm{Na}$ vizinha Bética, estão seguramente ligados a este tipo de actividades vários efectivos da gens Antonia, mercatores de azeite conhecidos pelas marcas anforárias recuperadas no Monte Testaccio (113). Do vasto conjunto, chamamos a atenção para o cordovêsL. Antonius Severus, para os astigitanos L. Antonius Epaphroditus e L. Antonius Iucundus e, sobretudo, para $Q$. Antonius Quietus, cuj as estampilhas em ânforas globulares Dressel 20 surgem espalhadas por todo o ocidente romano (114). A ocupações similares podem estar igualmente associados os magistrados gaditanos L. Antonius Antullus (115), Q. Antonius Rogatus (116) e M. Antonius Syriacus $\left({ }^{117}\right)$.

Para além dos aspectos já frisados, uma análise global do material epigráfico recolhido permite-nos constatar que pelo menos cerca de um

$\left.{ }^{108}\right)$ IRC-II 24: C. Antonius Verecundus: Ilvir bis, tribunus militum legionis III Augusta bis.

${ }^{(109)}$ Os magistrados de Clunia pertencentes à família Antonia (P. Antonius e M. Antonius) são conhecidos unicamente pelas legendas dos numismas cunhados durante o seu quatorvirato (cfr. BELTRÁN LlORIS, F., Los magistrados monetales en Hispania, "Numisma", 28, 1978, p. 194 e 206, notas 2 e 3).

(no) Idem, ibidem, p. 194. Mais um caso conhecido pelas emissões monetárias. Q. Antonius foi duúnviro da cidade antes de 27 a.C.

(m) AE 1984 568: L. Antonius Aquilus, Ilvir, tribunus militum.

(112) AE 1982 272: C. Antonius Aquilus, praefectus cohortis I Celtiberorum. Natural de Aova Augusta (conventus cluniensis), deve ser aparentado com L. Antonius Aquilus (nota 111). Em 132 d.C. celebrou um pacto de hospitium corn os Coelerni (cfr. TRANOY, Galice romaine, pp. 382-383).

(113) RODRÍGUEZ-ALMEIDA (E.), Monte Testaccio: i mercatores dell'olio della Betica, MEFRA, 91 (2), 1979, p. 885.

(114) BlÁZqueZ-MARTíneZ (J. M.), La exportación del aceite hispano en el Imperio romano. Estado de la cuestión, in "Producción y Comercio del Aceite en la Antigüedad. Primer Congreso Internacional”, I, Madrid, 1980, pp. 23-24.

$\left({ }^{115}\right)$ CIL II 1727 e 1728 = ILER 3783: sacerdos, IlIIvir aedilicia potestate.

(116) CIL II $1729=$ ILER 3544: decurio.

(ii) CIL II1313 = ILER 1679, 1503: Ilvir. 
quinto dos indivíduos registados no Quadro I são cidadãos romanos de pleno direito, privilégio confirmado pela presença de 21 referências expressas à tribo, a que devemos acrescentar vários casos em que esta não é indicada, mas que se podem considerar seguros, como os do olisiponense Q. Antonius Gallus e do novaugustano C. Antonius Aquilus.

Significativa é também a presença de numerosos ingenui, identificados pela simples menção da filiação, como sucede por exemplo, em Cádiz: M. Antonius M. $f$ Lucanus (CIL II1767 = ILER 3550); Barcino: Cn. Antonius Cn.f Onesimus (CILII 4560) e Briviesca: Antonius Paternus Paterni f. (AE 1977 454). Esta última forma de identificação está principalmente atestada nas áreas menos romanizadas, do Norte da Península, região onde podemos também encontrar o gentilicio associado a cognomina tipicamente indígenas '.Antonius Arquius (CILII 2633), Antonia Albiniana (CIL II2653), AntoniusAllionus (AE 1983 504), etc. São, no entanto, em maior número, os indivíduos que não revelam o seu estatuto sóciojurídico. Muitos deles, serão libertos e clientes dos vários ramos da família Antonia, disseminados pela Hispânia, por vezes reconhecíveis pela adopção de cognomes gregos, tais como Antonia Hellas (AE 1978 408),AntoniusAtimethus (CILII 532 = ILER4657) tAntonius Theophilus (CIL II1212 = ILER 4487), entre muitos outros. Porém, devemos fazer notar que o recurso aos tria nomina, sendo o cognome de etimologia grega, é insuficiente para comprovar a condição social dos seus portadores. Em muitos casos, sobretudo nas cidades portuárias, poderão identificar pessoas originárias da metade grega do Império, talvez comerciantes.

À guisa de conclusão, julgamos poder afirmar que, pelo seu elevado número, pelo seu significativo poder económico e pela excelência dos cargos desempenhados, esta foi uma das famílias com participação activa na romanização das províncias ibéricas, contribuindo de forma preponderante para a construção na Hispânia desse "admirável mundo novo", que deu pelo nome de Imperium Romanum. 


\title{
ABREVIATURAS BIBLIOGRÁFICAS
}

\author{
$\mathrm{AB}$ \\ Arquivo de Beja. Beja. \\ $\mathrm{AE}$ \\ L'Année Épigraphique. Revue de Publications Épigraphiques relatives \\ à L'Antiquité Romaine. Paris. \\ AncSoc Ancient Society. Lovaina. \\ AntAfr Antiquités Africaines. Paris. \\ AP \\ O Arqueólogo Português. Lisboa. \\ B CAR \\ Bulletino della Commissione Archeologica Comunale di Roma. Roma. \\ BRAH \\ Boletín de la Real Academia de Historia. Madrid. \\ CadArq Cadernos de Arqueologia. Braga. \\ CIL \\ $\mathrm{CPh}$ \\ Corpus Inscriptionum Latinarum. \\ Classical Philology. Chicago. \\ CPIL \\ DA Daremberg (Ch.), SAglio (E.), Potiter (E.), Dictionnaire des antiquités \\ Hurtado de SAn Antonio (R.), Corpus Provincial de las Inscripciones \\ Latinas (Cáceres). Cáceres, 1977. \\ grecques et romaines. Paris, 1877-1919. \\ EE Ephemeris Epigraphica. Berlim. \\ ELPS JiMENO (A.), Epigrafia Latina de la Provinda de Soria. Soria, 1980. \\ ELS BÉLTRAN LLORIS (F.), Epigrafia Latina de Sagunto y su territorium. \\ Valência, 1980. \\ EO Silva (A. V.), Epigrafia de Olisipo. Lisboa, 1944. \\ ERA Diego SAntos (F.), Epigrafia Romana de Asturias. Oviedo, 1959. \\ ERC BRANDÃo (D. P.), Epigrafia romana coliponense, "Conimbriga", 11, \\ 1972, pp. 41-192. \\ FE \\ Ficheiro Epigráfico. Suplemento de "Conimbriga". Coimbra. \\ HAE Hispania Antiqua Epigraphica. Suplemento de AEA. Madrid. \\ IDR Russu (I. I.), Inscriptiile D aciei Romane. Bucareste, 1975-1984. \\ ILER VIVES (J.), Inscripciones Latinas de la España Romana. Barcelona, \\ 1971 e 1972. \\ ILLRP DEgRASSI (A.), Inscriptiones Latinae Liberae Rei Publicae. Tomo I, \\ Florença-Gôttingen, 2- ed., 1975. Tomo II, Florença, 1963. \\ ILS DESSAU (H.), Inscriptiones Latinae Selectae. Dublin-Zurique, 1974 \\ (reed.).
}

Conimbriga, 31 (1992), 119-154 
IRC FABRe (G.), MAYer (M.), Roda (I.), Inscriptions Romaines de Catalogne. I-Barcelona (sauf Barcino). II-Lérida. Paris, 1985.

IRCP ENCARnaÇão (J. d'), Inscrições Romanas do Conventus Pacensis. Coimbra, 1984.

IRV Pereira Menaut (G.), Inscripciones Romanas de Valentia. Valência, 1979.

MCV Mélanges de la Casa de Velázquez. Madrid.

MEFRA Mélanges de L'École Française de Rome. Roma.

MHA Memorias de Historia Antigua. Oviedo.

PIR Groag (E.) e Stein (A.), Prosopographia Imperii Romani. BerlimLeipzig, 1933.

PLAV Papeles del Laboratorio de Arqueologia Valenciana. Valência.

RE Paulys Real-Encyclopädie der Classischen Altertumswissenchaft. Estugarda.

RIT AlföLDY (G.), Die Römischen Inschriften von Tarraco. Berlim, 1975.

TLL Thesaurus Linguae Latinae. 


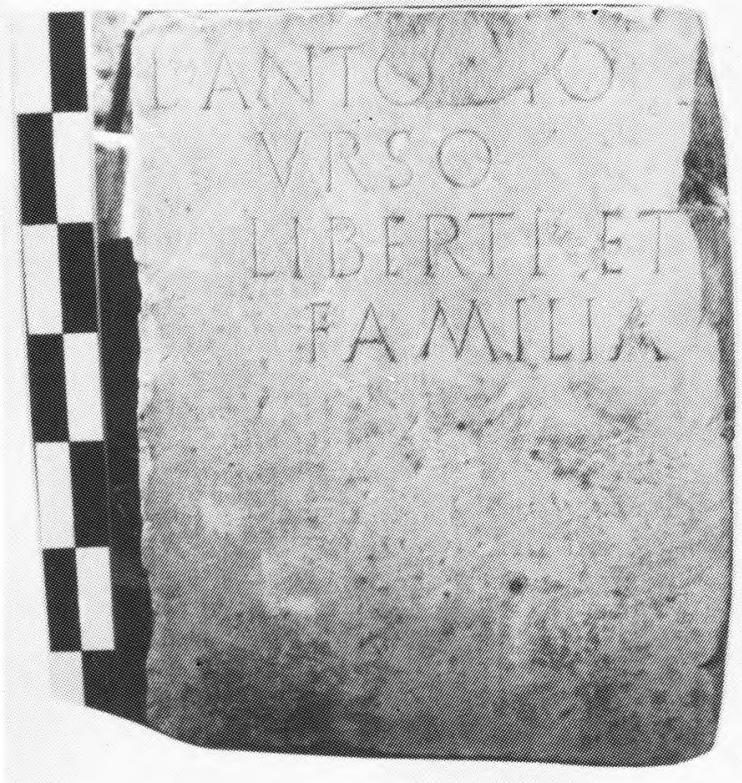

FIG. 1 
(Página deixada propositadamente em branco) 


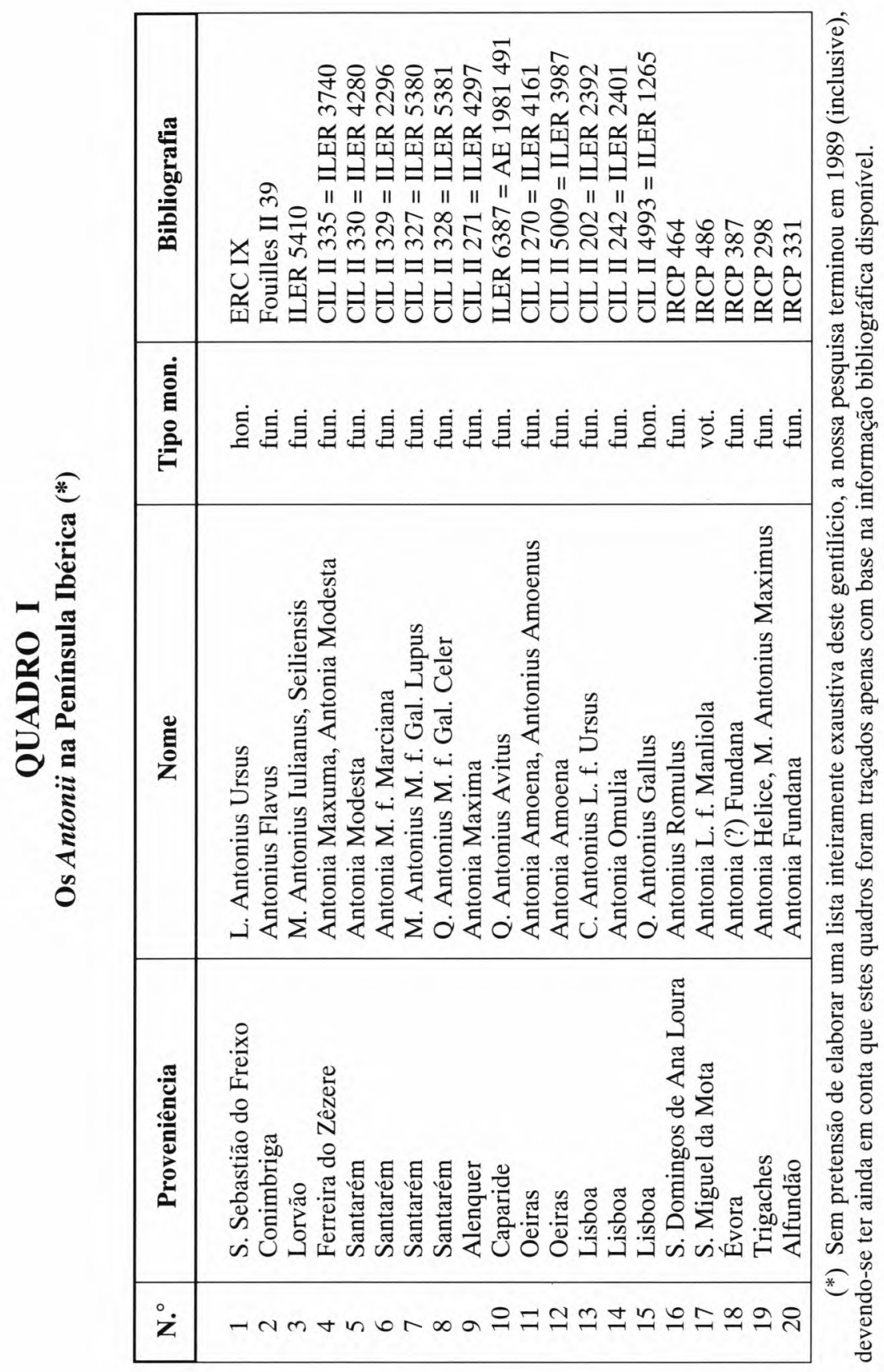




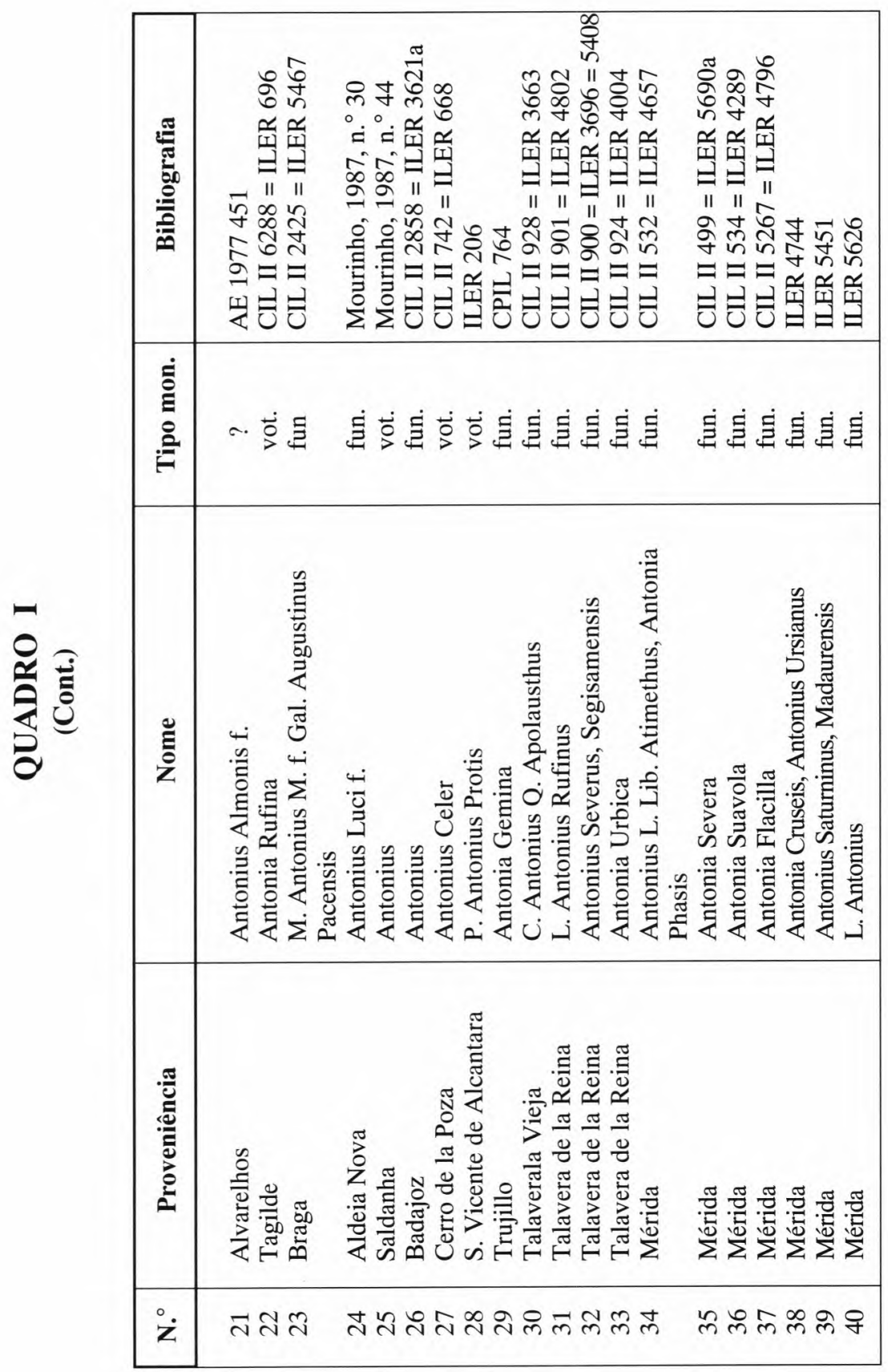




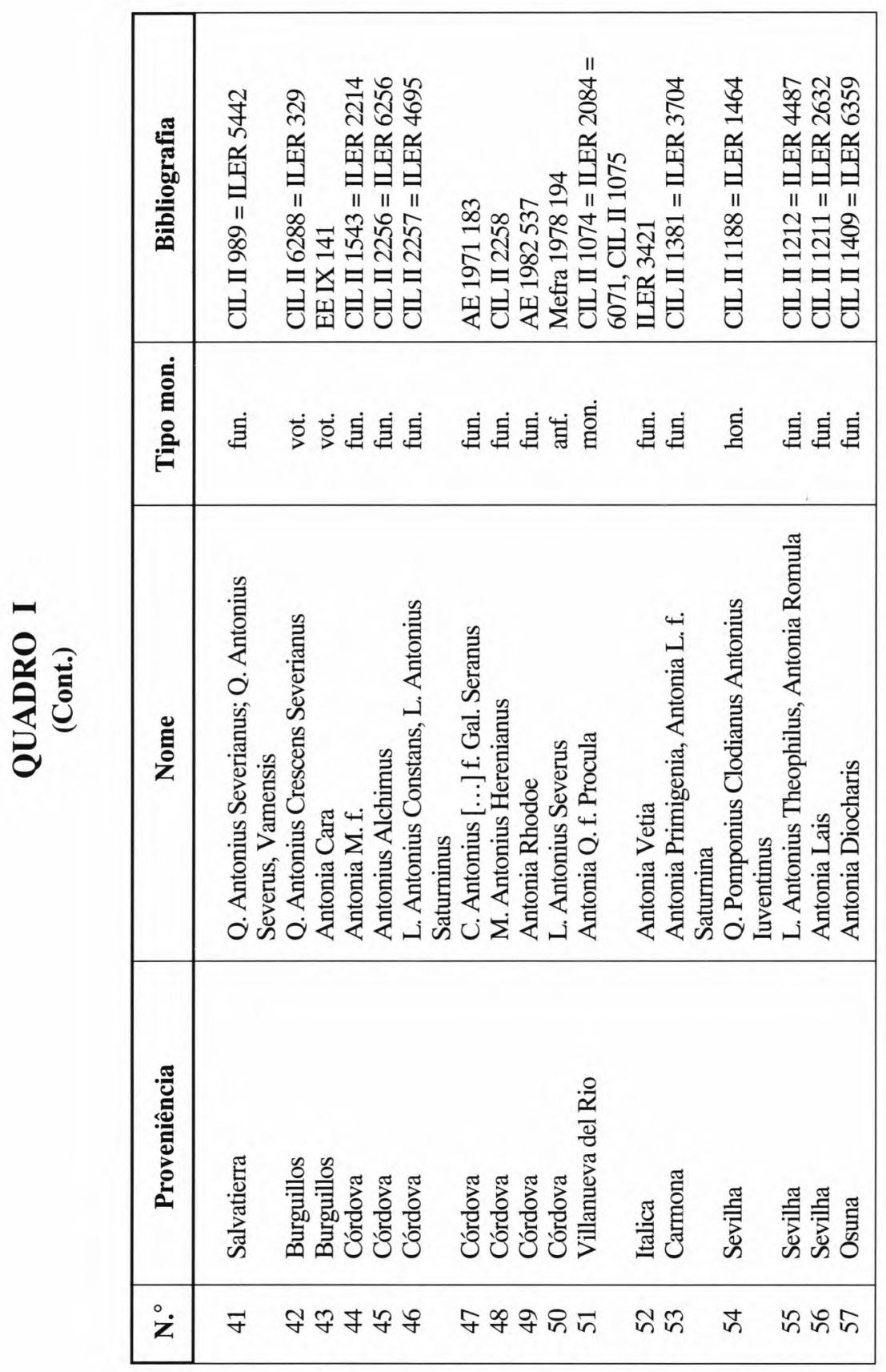




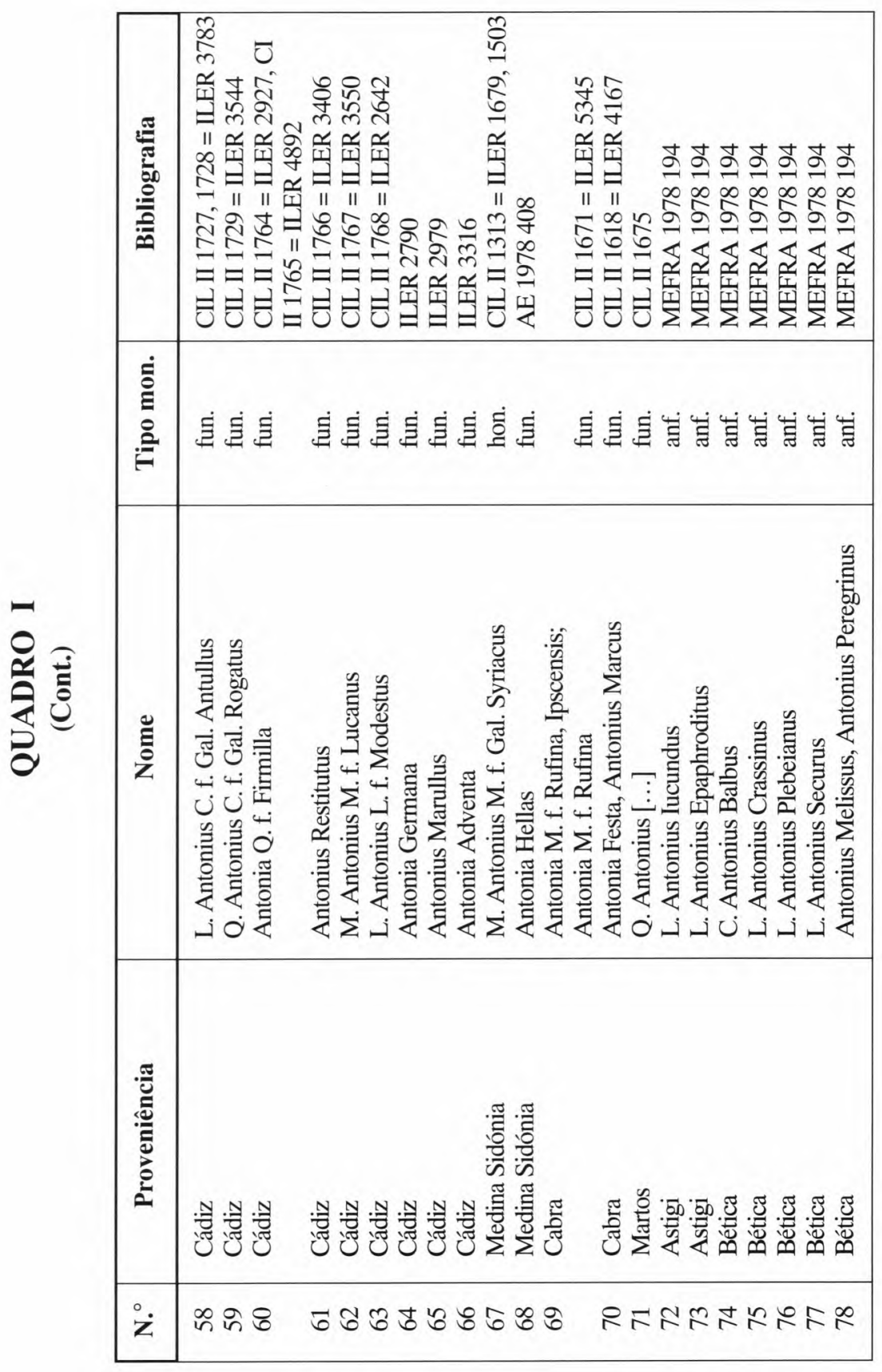




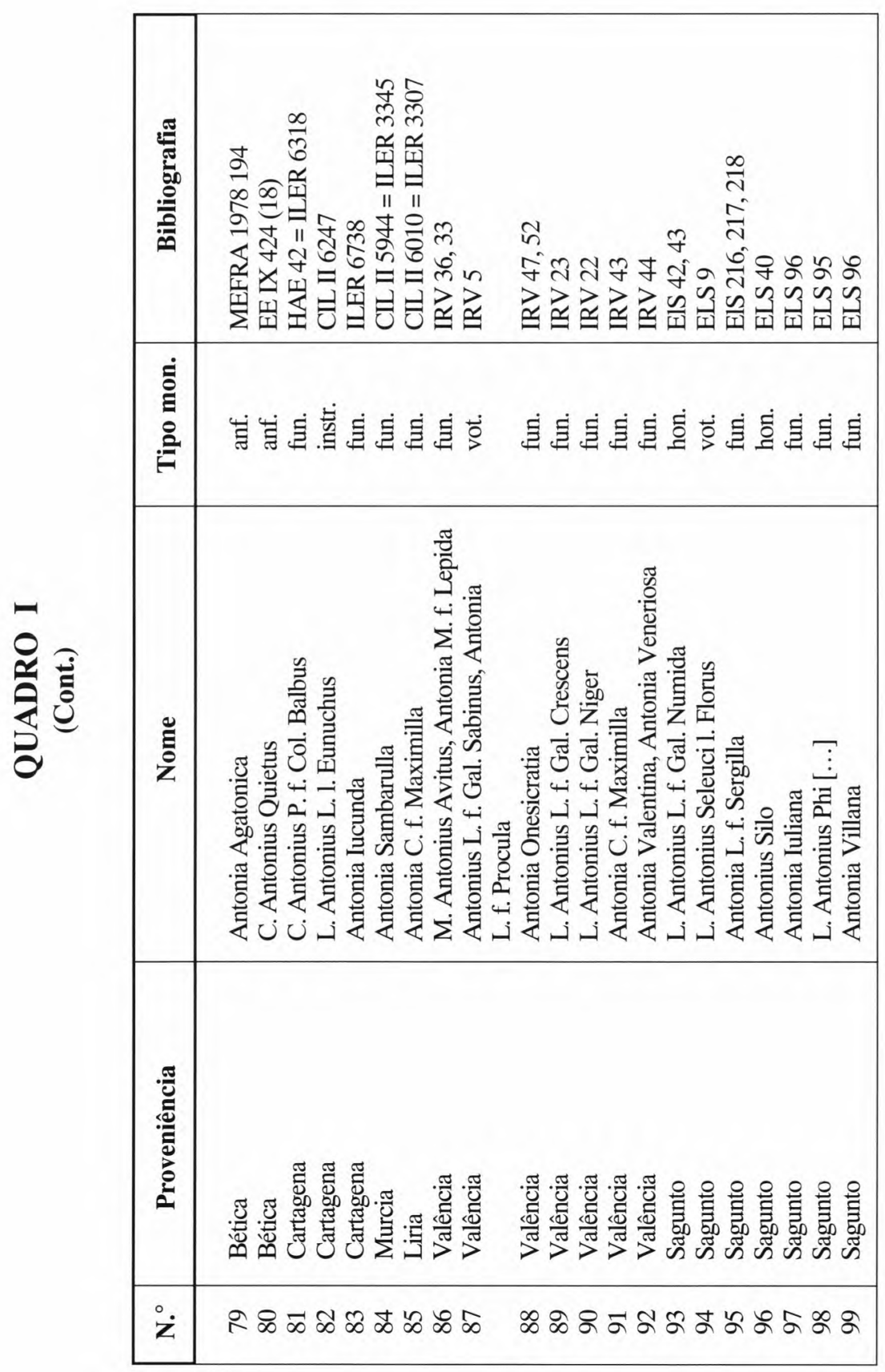




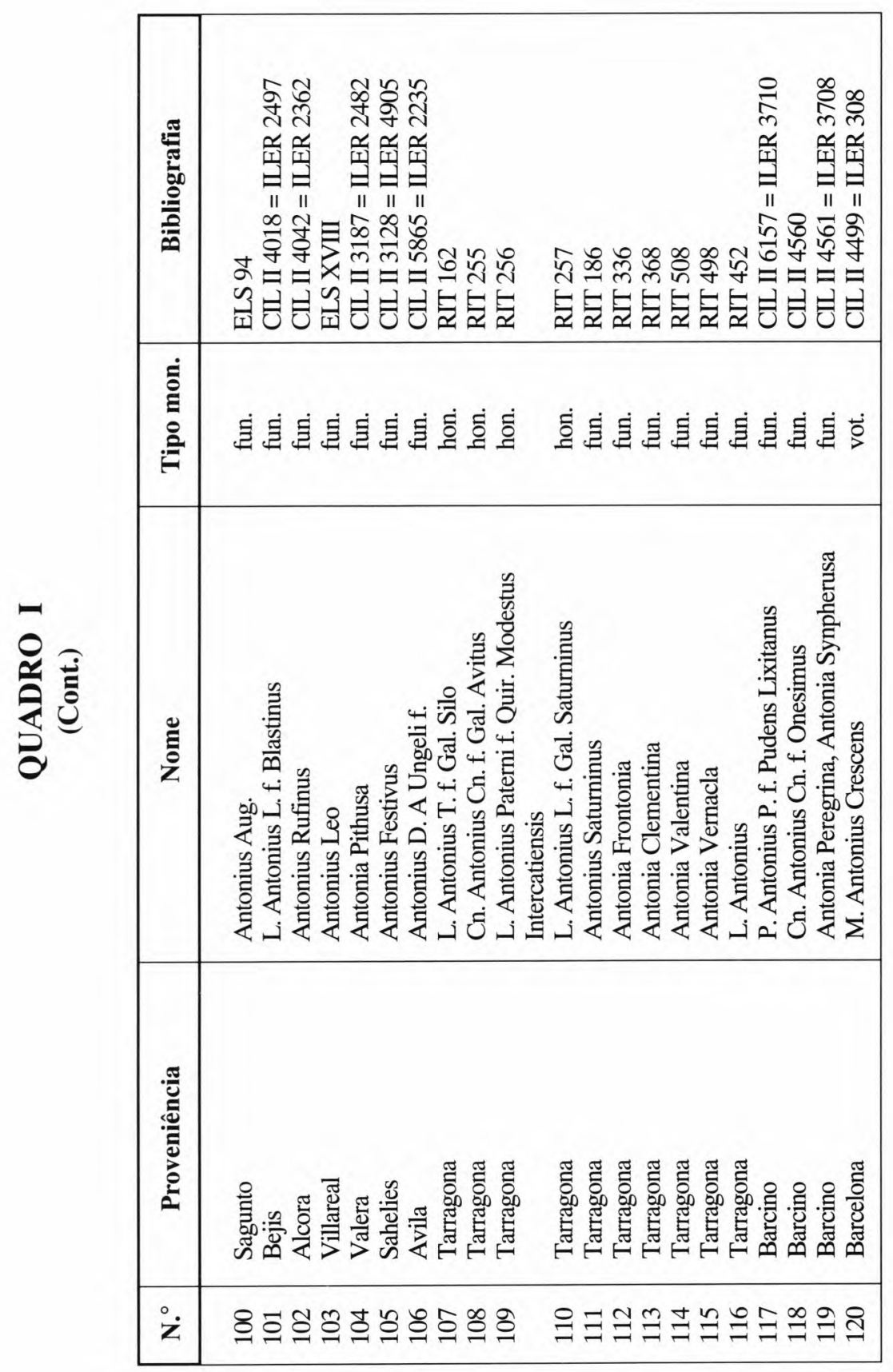




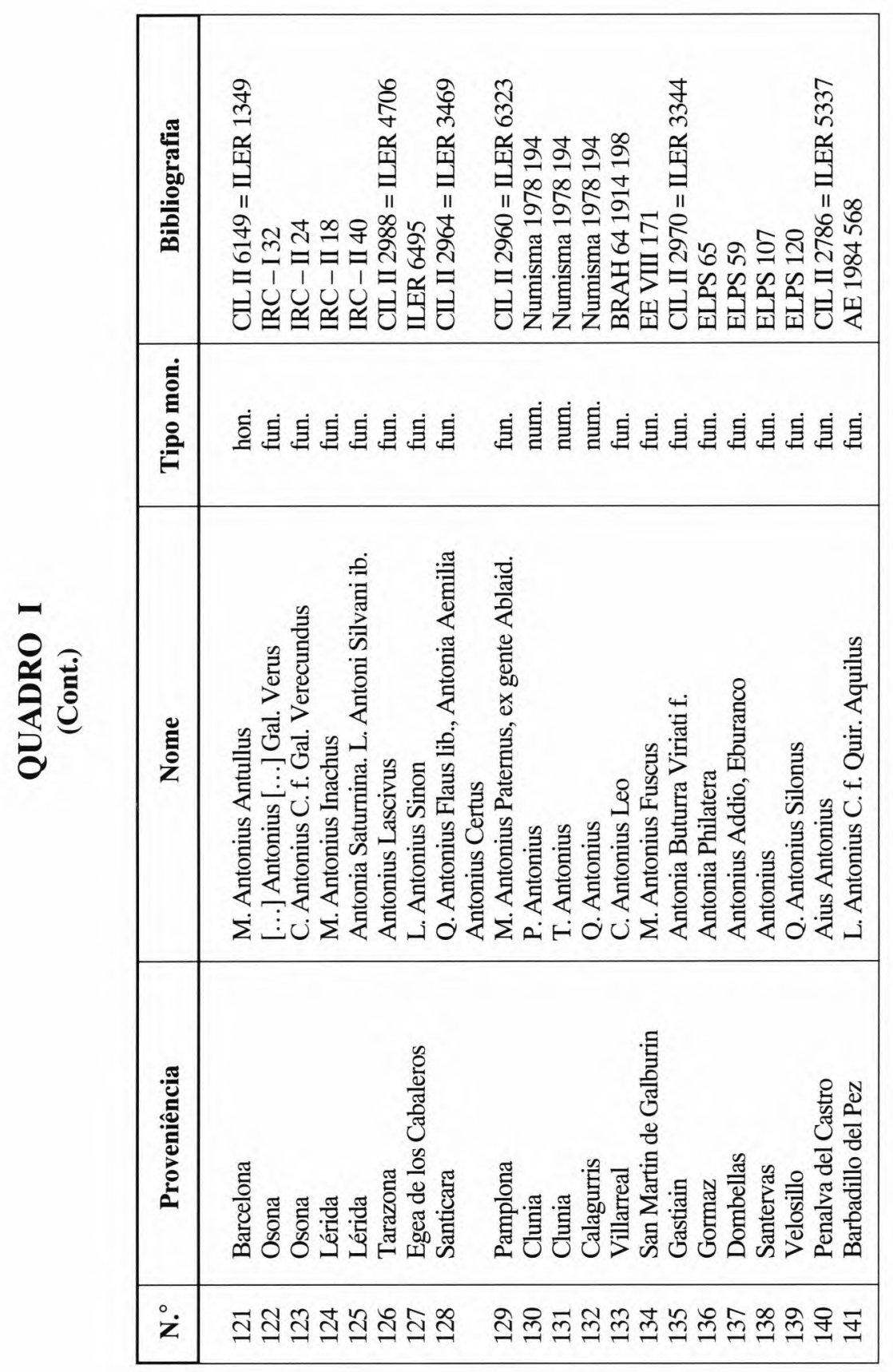




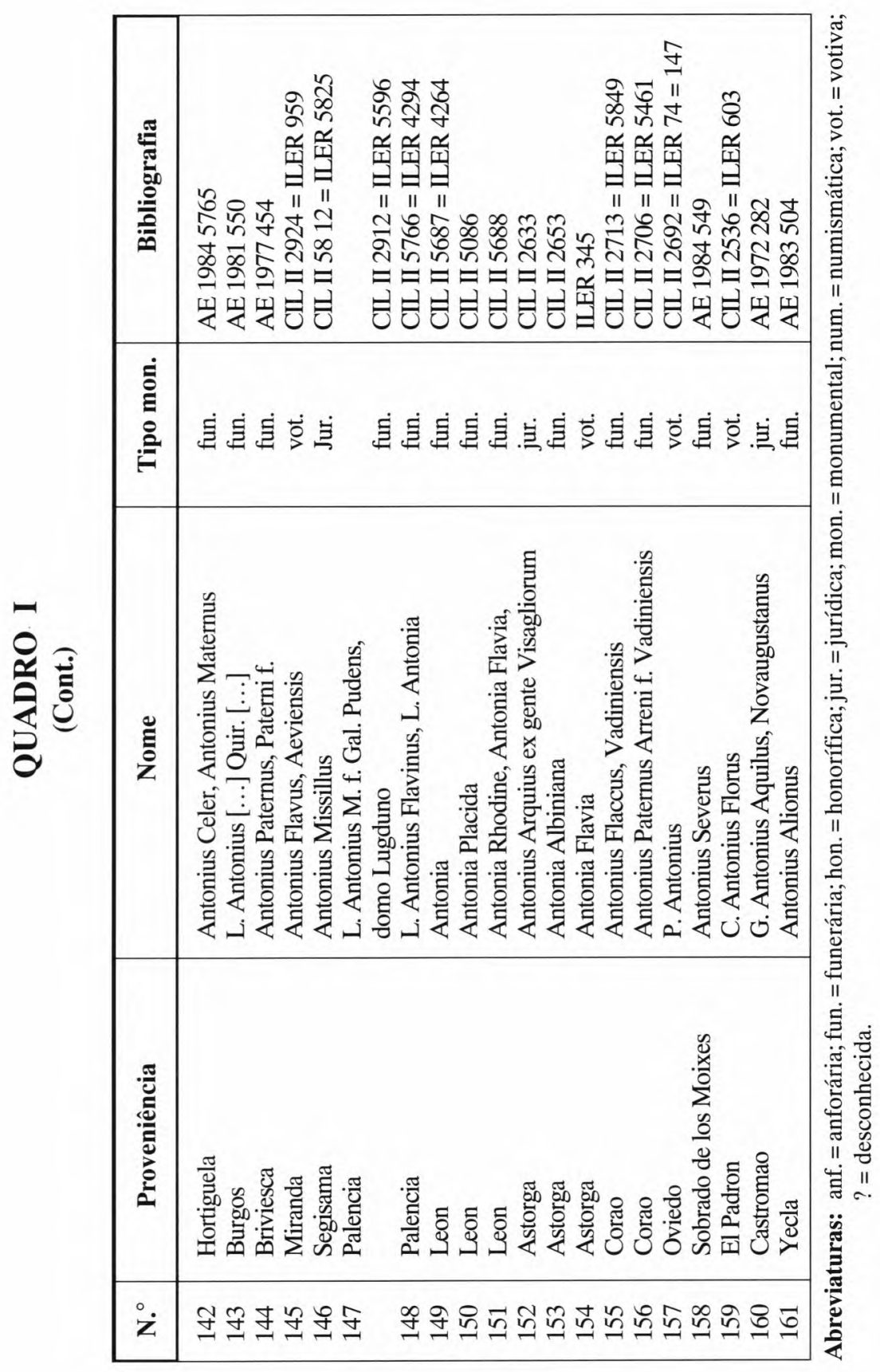




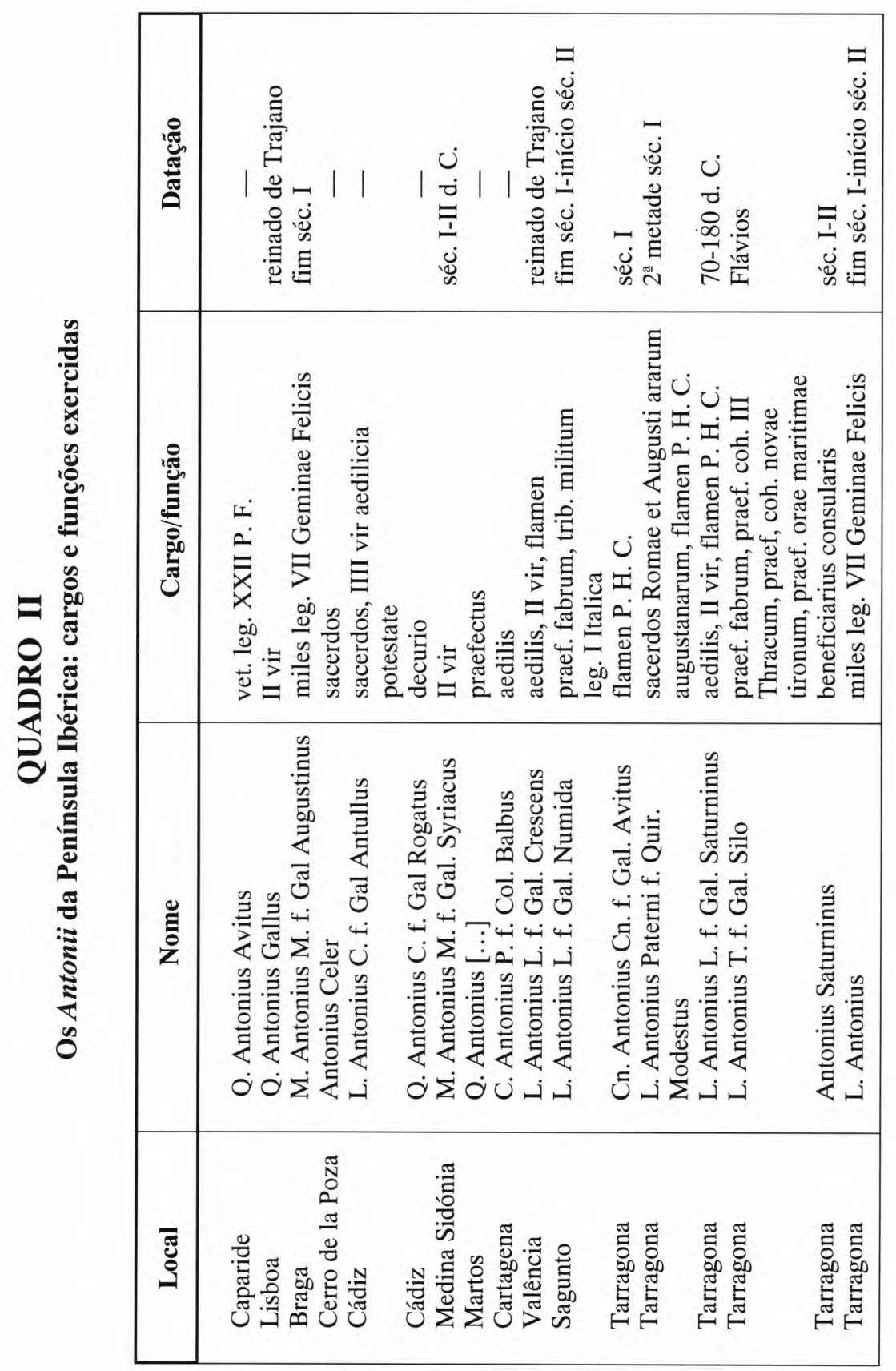




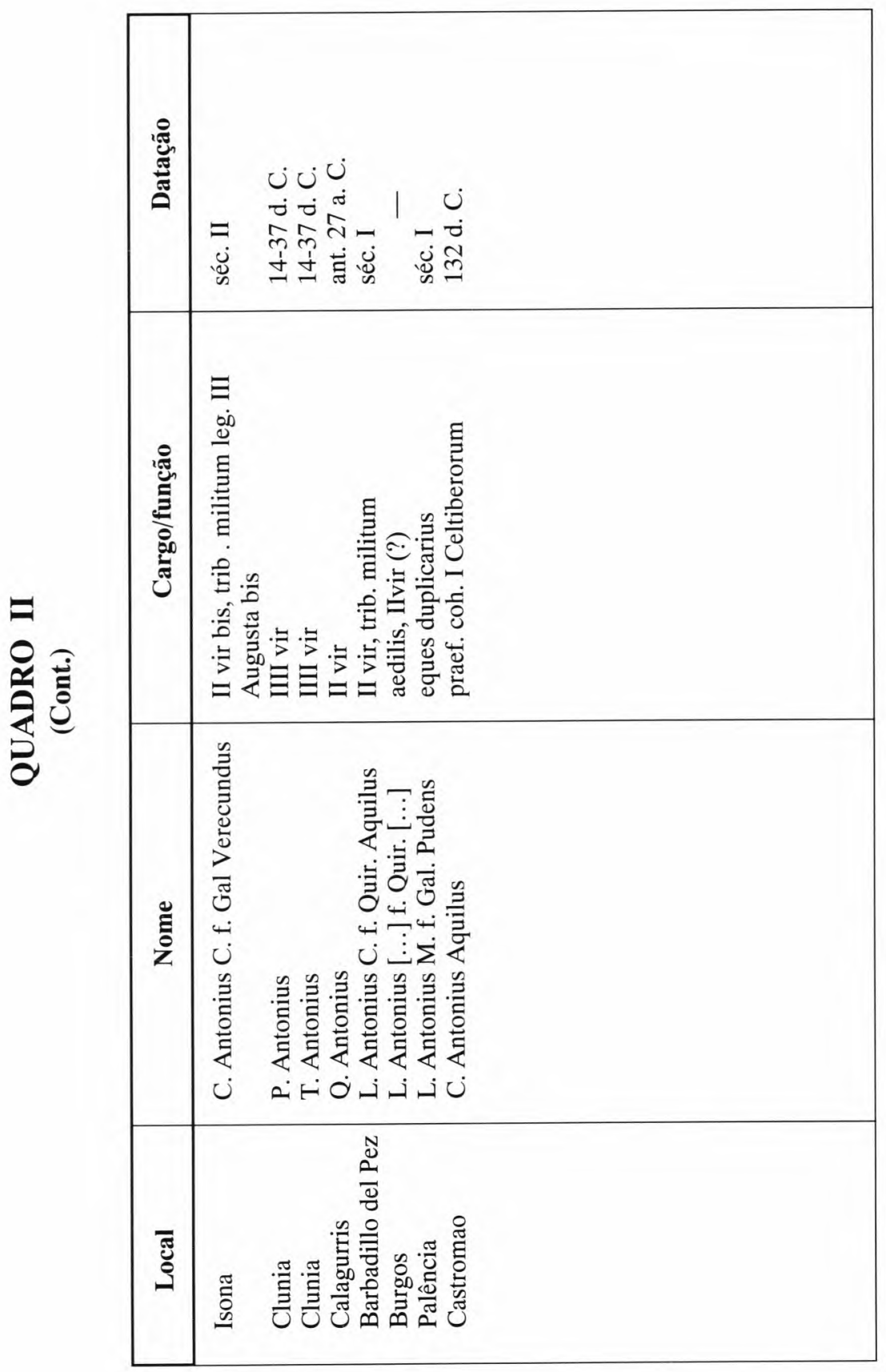

